\title{
Zur Kenntniss der Naphtoësänren;
}

\author{
von \\ A. G. Ekstrand. \\ (Schluss. ${ }^{1}$ )
}

Mononitro- $\alpha-n$ aphtoësäure vom Schmelzp. $239^{\circ}$.

Wie schon früher (S. 157) bemerkt, bilden sich beim Digeriren der $\alpha$-Naphtoësäure mit Salpetersäure vom spec. Gew. 1,41 zwei isomere Mononitrosäuren, von denen die eine im Vorigen geschildert worden ist; die andere war schwer löslich in Alkohol und krystallisirte daraus in feinen, gelblich weissen Nadeln, die nach wiederholtem Umkrystallisiren bei $239^{\circ}$ schmolzen. Die Säure fordert zum Lösen 187 Thle. käuflichen Alkohol und 4820 Thle. Wasser, beide von gewöhnlicher Temperatur. In warmem Alkohol, Aether, Eisessig und Benzol ist sie sehr leicht löslich, und eine heisse alkoholische Lösung erstarrt fast beim Erkalten; auch in heissem Wasser ist sie ziemlich löslich und scheidet sich beim Abkühlen in voluminösen Flocken von langen Nädelchen ab. Sie lässt sich auch sublimiren, und tritt dann ebenfalls in feinen Nadeln auf.

24,1364 Grm. einer bei gewöhnlicher Temperatur gesättigten alkoholischen Lösung gaben 0,1284 Grm. Rückstand.

36,1928 Grm. einer bei Zimmertemperatur gesättigten Wasserlösung gaben 0,0075 Grm. Rückstand.

$0,1500 \mathrm{Grm}$. gaben bei $11^{\circ}$ und $768,3 \mathrm{Mm} .8,6 \mathrm{Ccm}$. N.

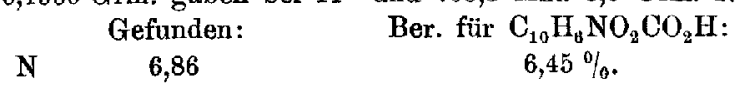

Der Aethyläther krystallisirte aus Alkohol in langen, verfilzten, fast farblosen Nadeln vom Schmelzp. $92^{\circ}-93^{\circ}$.

$0,2600 \mathrm{Grm}$. gaben 0,6030 Grm. $\mathrm{CO}_{2}$ und 0,1185 Grm. $\mathrm{H}_{2} \mathrm{O}$.

$\begin{array}{ccc} & \text { Gefunden: } & \text { Ber. für } \mathrm{C}_{10} \mathrm{H}_{6} \mathrm{NO}_{2} \mathrm{CO}_{2} \mathrm{C}_{2} \mathrm{H}_{5}: \\ \text { C } & 63,27 & 63,67 \% \\ \mathrm{H} & 5,03 & 4,49 \%\end{array}$

Das Natriumsalz, $\mathrm{C}_{10} \mathrm{H}_{6} \mathrm{NO}_{2} \mathrm{CO}_{2} \mathrm{Na}+5 \mathrm{H}_{2} \mathrm{O}$, ist sehr leicht löslich auch in kaltem Wasser und krystallisirt beim Verdunsten des Wassers in gelben, feinen Nadeln.

1) Vergl. S. $139-185$.

Journal f. praist. Chemje [2] Bd. 38. 
242 Ekstrand: Zur Kenntniss der Naphtoësäuren.

1. 0,5556 Grm. des zwischen Löschpapier getrockneten Salzes verloren beim Erhitzen auf $140^{\circ} 0,1538$ Grm. $\mathrm{H}_{2} \mathrm{O}=27,680_{0}^{\circ}$; ber. $27,38 \% \mathrm{H}_{2} \mathrm{O}$.

2. 0,0796 Grm. des wasserfreien Salzes gaben 0,0248 Grm. $\mathrm{Na}_{2} \mathrm{SO}_{4}=10,05 \% \mathrm{Na}$; ber. $9,62 \% \mathrm{Na}$.

Das Calciumsalz, $\left(\mathrm{C}_{10} \mathrm{H}_{6} \mathrm{NO}_{2} \mathrm{CO}_{2}\right)_{2} \mathrm{Ca}+2 \mathrm{H}_{2} \mathrm{O}$, erhalten durch Kochen der Säure mit Wasser und Calciumcarbonat, bildete gelbe Krystallnadeln, die in kaltem Wasser ziemlich schwer löslich waren.

0,4157 Grm., zwischen Löschpapier getrocknet, verloren bei $130^{\circ}$ 0,0295 Grm. $\mathrm{H}_{4} \mathrm{O}=7,09 \%$; ber. $7,00 \% \mathrm{H}_{2} \mathrm{O}$; der Rückstand, 0,3862 Grm., gab 0,1110 Grm. $\mathrm{CaSO}_{4}=8,44 \% \mathrm{Ca}$; ber, $8,36 \% \mathrm{Ca}$.

Das Baryumsalz, $\left(\mathrm{O}_{10} \mathrm{H}_{6} \mathrm{NO}_{2} \mathrm{CO}_{2}\right)_{2} \mathrm{Ba}+31 / 2 \mathrm{H}_{2} \mathrm{O}$, durch Kochen der Säure mit Wasser und Baryumcarbonat erhalten, bildete gelbe Nadeln, die in kaltem Wasser ziemlich löslich waren.

0,6903 Grm, zwischen Löschpapier getrocknet, verloren bei $140^{\circ}$ $0,0666 \mathrm{Grm} . \mathrm{H}_{2} \mathrm{O}=9,64 \%$; ber. $9,96 \% \mathrm{H}_{2} \mathrm{O}$; der Rüickstand, $0,6237 \mathrm{Grm}$., gab 0,2613 Grm. $\mathrm{BaSO}_{4}=24,62^{\circ}$ : Ba; ber, 24,07\% Ba.

Von Graeff ${ }^{1}$ ) ist ein anderes Baryumsalz erhalten worden, dem er die Zusammensetzung:

$$
5\left[\left(\mathrm{C}_{10} \mathrm{H}_{6} \mathrm{NO}_{2} \mathrm{CO}_{2}\right)_{2} \mathrm{Ba}\right]+\mathrm{BaO}+10 \mathrm{H}_{2} \mathrm{O}
$$

zuschreibt; diese Formel ist allerdings etwas eigenthümlich, and bei meinem Versuche, obwohl ich in derselben Weise verfahren habe wie Graeff, ist kein derartiges Salz erhalten worden.

Das Bleisalz. war zu schwer löslich, um durch Kochen der Säure mit Wasser und Bleicarbonat erhalten zu werden, es wurde daher aus einer heissen Lösung des Baryumsalzes mit Bleiacetat gefällt und bildete einen fast weissen Niederschlag, der aus mikroskopischen Nadelı bestand. Die Analyse führte zur Formel: $\left(\mathrm{C}_{10} \mathrm{H}_{6} \mathrm{NO}_{2} \mathrm{CO}_{2}\right)_{2} \mathrm{~Pb}+5^{1} / 2 \mathrm{H}_{2} \mathrm{O}$.

$0,4158 \mathrm{Grm}$. , getrocknet zwischen Löschpapier, verloren bei $150^{\circ}$ $0,0550 \mathrm{Grm} . \mathrm{H}_{2} \mathrm{O}=13,22 \%$; ber. $13,41 \% \mathrm{H}_{2} \mathrm{O}$; der Rückstand, $0,3608 \mathrm{Grm}$., gab 0,1672 Grm. $\mathrm{PbSO}_{4}=31,65 \% \mathrm{~Pb}$; ber. $32,39 \% \mathrm{~Pb}$.

1) Zur Kenutniss der Mononitronaphtalinearbonsäuren. Habilitationsschrift, Freiburg i. B. 1883. 
Graeff hat auch ein Kaliumsalz,

$$
\mathrm{C}_{111} \mathrm{H}_{6} \mathrm{NO}_{2} \mathrm{CO}_{2} \mathrm{~K}+\mathrm{H}_{3} \mathrm{O}
$$

dargestellt und analysirt.

Ebenfalls sind von ihm einige A ether dargestellt worden, wie der Methyläther vom Schmelzp. $109^{\circ}-110^{\circ}$, der Aethyläther vom Schmelzp. $93^{\circ}$ und der Isopropyläther vom Schmelzp. 101,5 $5^{\circ}$.

Das Nitril, $\mathrm{C}_{10} \mathrm{H}_{6} \mathrm{NO}_{2} \mathrm{CN}$, ist von Graeff neben anderen Produkten beim Nitriren des $\alpha$-Naphtonitrils erhalten worden; sein Schmelzp. liegt bei 205".

Was die Stellung der Nitrogruppe in dieser Nitro- $\alpha$ naphtoësäure anbetrifft, so hat $\mathrm{G} \mathrm{raeff^{1 } )}$ die Nitrosäure theils mit Kaliumpermanganat in alkalischer Lösung, theils mit Salpetersäure vom spec. Gew. 1,12 behandelt und in beiden Fällen eine Nitrophtalsäure vom Schmelzp. $212^{\circ}$ (Schmelzp. des Anhydrides $163^{\circ}-164^{\circ}$ ) erhalten, in welcher die beiden Carboxyl- und die Nitrogruppe die Stellungen 1.2. 3. einnehmen. Um womöglich die Carboxylgruppe in der Nitronaphtoësäure durch eine Nitrogruppe zu substituiren, habe ich die Säure mit einem Ueberschusse an Salpetersäure vom spec. Gew. 1,3 erhitzt, bis sich alles gelöst hatte, was längere Zeit forderte. Nach dem Erkalten wurde mit Wasser verdünnt, wobei ein Niederschlag von Krrystallnadeln entstand. Beim Digeriren mit Sodalösung blieb ein Theil des Niederschlags ungelöst zurück und zeigte nach wiederholtem Umkrystallisiren aus Alkohol den Schmelzp. 211 $-212^{\circ}$. Es war also das $\alpha$-Dinitronaphtalin, das nach Beilstein und Kurbatow ${ }^{2}$ ) bei $211^{0}$, nach $A$ guiar ${ }^{3}$ ) bei $216^{\circ}$ schmelzen soll, und dessen Constitution man durch die Formel:

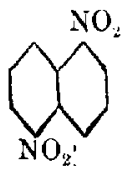

auszudrücken gewohnt ist. Dem gegenüber sind Beilstein und $\mathrm{Kurbatow}$ durch ihre Oxydationsversuche mit Salpeter-

1) Ber. 15, 1127 .

2) Ann. Chem. 202, 219.

3) Ber. 5, 372 . 


\section{Ekstrand: Zur Kenntmiss der Naphtoësäuren.}

säure zu der Ansicht gelangt, dass zwar die beiden Nitrogruppen in verschiedenen Benzolkernen stehen müssen, glauben aber die Möglichkeit einräumen zu sollen, dass die eine Nitrogruppe in $\beta$-Stellung eingetreten ist, was jedoch hinfällig erscheint, nachdem Atterberg ${ }^{1}$ ) aus dem $\alpha$-Dinitronaphtalin das $\gamma$-Dichlornaphtalin erhalten hat, worin nach $\mathrm{Cleve}^{2}$ ) die zwei Chloratome unzweifelhaft $\alpha$-Stellungen einnehmen.

Die hier in Rede stehende Nitro- $\alpha$-naphtoësäure hat daher auch ihre Substituenten in $\alpha$-Stellungen und muss somit entweder

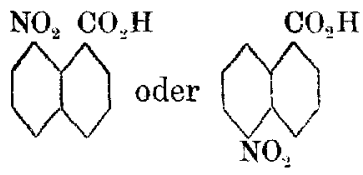

sein. Die erste Formel kommt, wie schon gezeigt, wit aller Wahrscheinlichkeit der isomeren Nitrosäure vom Schmelzp. $215^{\circ}$ zu; für die Nitrosäure vom Schmelzp. $239^{\circ}$ bleibt daher nur die letzte Formel übrig, was wiederum die alten Formeln des $\alpha$-Dinitronaphtalins und des $\gamma$-Dichlornaphtalins bestätigt.

Amido- $\alpha$-naphtoësäure rom Schmelzp. $211^{\circ}-212^{0}$.

Die obige Nitro- $\alpha$-naphtoësäure wurde in überschüssigem Ammoniak gelöst und mit Ferrosulfat reducirt, wie für die isomere Amidosäure angegeben worden ist (S. 159). Das Filtrat vom ausgeschiedenen Ferrihydrat wurde mit Essigsäure angesäuert, wonach die Lösung sich bald mit feinen Krystallnadeln erfüllte. Diese Krystalle waren anfangs farblos, gingen aber nach und nach in Violett über. Der Schmelzpunkt lag nach dem Umkrystallisiren aus Alkohol bei $211^{\circ}-212^{\prime \prime}$.

1. $0,2162 \mathrm{Grm}$. gaben $0,5558 \mathrm{Grm} . \mathrm{CO}_{2}$ und $0,0996 \mathrm{Grm} . \mathrm{H}_{2} \mathrm{O}$.

2. $0,3296 \mathrm{Grm}$., nach Kjeldahl's Methode behandelt, gaben 0,02433 Grm. N.

3. 0,2156 Grm. gaben nach derselben Methode $0,01622 \mathrm{~N}$.

1) Ber. 9, 1188.

2) Das. 9, 1734 . 
Ekstrand: Zur Kenntniss der Naphtoësäuren.

\begin{tabular}{ccccc} 
& \multicolumn{3}{c}{ Gefunden: } & Berechnet für: \\
& 1. & 2. & 3. & $\mathrm{C}_{10} \mathrm{H}_{6} \mathrm{NH}_{2} \mathrm{CO}_{2} \mathrm{H}$ \\
$\mathrm{C}$ & 70,12 & - & - & $70,58 \%$ \\
$\mathrm{H}$ & 5,11 & - & - & $4,81 \%$ \\
$\mathrm{~N}$ & - & $\mathbf{7 , 3 8}$ & $\mathbf{7 , 5 2}$ & $\mathbf{7 , 4 8} \%$
\end{tabular}

Die Amidosäure löste sich unbedeutend in Aether, etwas mehr in Alkohol und Eisessig; sie war auch etwas löslich in kochendem Wasser, aber die daraus krystallisirende Verbindung hatte nicht mehr den Schmelzpunkt der Amidosäure; or lag nämlich bei $198^{\circ}-199^{\circ}$ und blieb auch nach dem Umkrystallisiren unverändert.

Beim Erhitzen über den Schmelzpunkt sublimirte die Säure in gelben Nadeln, die gegen $196^{\circ}$ schmolzen. Es scheint daher, als ob die Amidosäure leicht in eine andere Verbindung von niedrigerem Schmelzpunkte übergehen kann, was jedoch bis jetzt nicht näher untersucht worden ist.

Das Calciumsalz, $\left(\mathrm{C}_{10} \mathrm{H}_{6} \mathrm{NH}_{2} \mathrm{CO}_{2}\right)_{2} \mathrm{Ca}+3 \mathrm{H}_{2} \mathrm{O}$, wurde durch Kochen der Säure mit Kalkmilch und Entfernung des Kalküberschusses durch Kohlendioxyd erhalten; es war sehr leicht löslich und bildete harte, etwas violettgefärbbte Nadeln.

0,2394 Grm., zwischen Löschpapier getrocknet, verloren beim Erhitzen auf $135^{\circ} 0,0296$ Grm. $\mathrm{H}_{2} \mathrm{O}=12,36 \%_{0}^{\circ}$; ber. $11,58 \% \mathrm{H}_{2} \mathrm{O}$; der Rückstand, 0,2098 Grm., gab 0,0707 Grm. $\mathrm{CaSO}_{4}=9,910_{0}^{0} \mathrm{Ca} ;$ ber. $9,73_{: 0}^{0_{i}} \mathrm{Ca}$.

\section{Monacetylamido- $\alpha$-naphtoësäure, $\mathrm{C}_{10} \mathrm{H}_{6} \mathrm{NH} \cdot \mathrm{C}_{2} \mathrm{H}_{3} \mathrm{O} \cdot \mathrm{CO}_{2} \mathrm{H}$,} wurde beim Kochen der Amidosäure mit Essigsäureanhydrid gebildet. Nachdem alles gelöst war, wurde das überschüssige Essigsäureanhydrid durch Verdunsten unter Zusatz von Alkohol entfernt und der Rückstand in heissem Alkohol gelöst; daraus setzte sich ein krystallinisches Pulver ab, das aus mikroskopischen Nadeln bestand. Der Schmelzpunkt lag über $280^{\circ}$.

0,1444 Grm. gaben 0,3606 Grm. $\mathrm{CO}_{2}$ und 0,0690 Grm. $\mathrm{H}_{2} \mathrm{O}$.

$\begin{array}{ccc} & \text { Gefunden: } & \text { Berechnet: } \\ \text { C } & 68,07 & 68,12 \% \\ \text { H } & 5,26 & 4,80 \%\end{array}$


246 Ekstrand: Zur Kenntniss der Naphtoësäuren.

Die Amidosäure geht auch mit stärkeren Säuren, wie Chlorwasserstoff-, Schwefel- und Salpetersäure, salzartige Verbindungen ein.

Das Chlorhydrat, $\mathrm{C}_{10} \mathrm{H}_{6} \mathrm{NH}_{2} \mathrm{CO}_{2} \mathrm{H}$. HCl. Beim Kochen mit Chlorwasserstoffsäure löste sich allmählich die Amidosäure, und aus dieser Lösung krystallisirten beim Erkalten lange, schwach violettgelbe Nadeln, die in kaltem Wasser schwer, in warmem aber ziemlich löslich waren; auch in Alkohol war die Verbindung löslich. Der Schmelzpunkt lag über $290^{\circ}$. Krystallisirte ohne Krystallwasser.

0,2393 Grm. gaben 0,1569 Grm. AgCl.

$$
\begin{array}{cc}
\text { Gefunden: } & \text { Berechnet: } \\
\mathrm{HCl} 16,63 & 16,33 \%
\end{array}
$$

Das Sulfat, $\left(\mathrm{C}_{10} \mathrm{H}_{6} \mathrm{NH}_{2} \mathrm{CO}_{2} \mathrm{H}\right)_{2} \mathrm{H}_{2} \mathrm{SO}_{4}$, wurde durch Kochen der Amidosäure mit verdünnter Schwefelsäure erhalten. Aus der filtrirten Lösung setzten sich röthliche, büschelförmig vereinigte Nadeln $a b$, die in Wasser und Alkohol schwerer löslich waren, als das Chlorhydrat. Beim Erhitzen auf $280^{\circ}$ schien Zersetzung einzutreten. Enthielt kein Krystallwasser.

1. 0,0922 Grm. gaben 0,1878 Grm. $\mathrm{CO}$ und 0,0363 Grm. $\mathrm{H}_{2} \mathrm{O}$.

2. 0,1755 Grm. gaben 0,0935 Grm. $\mathrm{BaSO}_{4}$.

Gefunden; 1.

C $\quad 55,55$

$\mathrm{H} \quad 4,33$

$\mathrm{H}_{2} \mathrm{SO}_{4} \quad-$

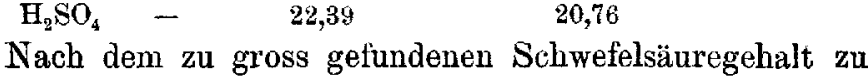
schliessen, muss die analysirte Substanz trotz des Auswaschens mit Wasser mechanisch anhaftende Schwefelsäure enthalten haben.

Das Nitrat, $\left(\mathrm{C}_{10} \mathrm{H}_{6} \mathrm{NH}_{2} \mathrm{CO}_{2} \mathrm{H}\right) \mathrm{HNO}$. In verdünnter Salpetersäure löst sich die Amidosäure beim Erwärmen ziemlich leicht; das Nitrat krystallisirte in langen, violetten Nadeln.

0,2023 Grm., bei $100^{\circ}$ getrocknet, gaben 0,3954 Grm. $\mathrm{CO}_{2}$ und 0,0755 Grm. $\mathrm{H}_{2} \mathrm{O}$.

$\begin{array}{ccc} & \text { Gefunden: } & \text { Berechnet: } \\ \text { O } & 53.28 & 52,80 \% \\ \text { II } & 4.15 & 4.00 \%\end{array}$


Ekstrand: Zur Kenntniss der Naphtoësäuren.

Die Verbindung fing schon gegen $220^{\circ}$ an unter Zersetzung zu schmelzen. Sie war in Alkohol sehr leicht löslich.

Nitroacetamido- $\alpha-n a p h$ toësäure vom Schmelzp. $258^{\circ}$.

Die Amido- $\alpha$-naphtoësäure vom Schmelzpunkt $211^{\circ}$ wurde mit Essigsäureanhydrid am Rückflusskühler erhitzt und das gewonnene Acetamidoderivat in Eisessig gelöst. Diese Lösung wurde nachher mit Salpetersäure vom spec. Gew. 1,42 versetzt und auf dem Wasserbade gelinde erwärmt. Bald schossen kleine, gelbe Krystallnadeln an, die, von der Mutterlauge befreit, aus Alkohol umkrystallisirt wurden. Die Farbe der so gereinigten Säure war weisslichgelb, und der Schmelzpunkt lag bei 259". In Alkohol war die Säure leicht löslich.

0,1727 Grm. gabeu bei $21, b^{\prime \prime}$ und 761,3 Mm. 15,4 Ccm. N.

$$
\text { N } \begin{gathered}
\text { Gefunden: } \\
10,40
\end{gathered} \quad \text { Ber. f. } \mathrm{C}_{1 n} \mathrm{H}_{3} \mathrm{NO}_{2} \mathrm{NH} . \mathrm{C}_{2} \mathrm{H}_{3}\left(1, \mathrm{CO}_{2} \mathrm{H}\right.
$$

Einwirkung von Chlor auf die Amido-c-naphtoësäure vom Schmelzp. $211^{\circ}$.

Dichlornaphtochinon- $\alpha$-carbonsänre.

Beim Einleiten von Chlorgas in eine mit etwas Jod versetzte heisse Eisessiglösung dieser Amidosäure trat bald eine eigenthümliche Reaction ein, indem sich ein krystallinisches Pulver abschied, welches gegen $260^{\circ}$ schmolz. Das Pulver war schwer löslich in Eisessig und wurde daher durch Auskochen damit gereinigt. Die Farbe war fast chocoladebraun.

1. $0,2070 \mathrm{Grm}$. gaben bei $11,2^{\circ}$ und $751,9 \mathrm{Mm} .13 \mathrm{Cem} . \mathbf{N}$.

2. $0,2190 \mathrm{Grm}$. gaben $0,3287 \mathrm{Grm}$. AgCl.

3. 0,2284 Grm. gaben 0,2870 Grm. $\mathrm{CO}_{2}$ und 0,0766 Grm. $\mathrm{H}_{2} \mathrm{O}$.

\begin{tabular}{ccccc} 
& \multicolumn{3}{c}{ Gefunden: } & Berechnet für: \\
& 1. & 2. & 3. & $\mathrm{C}_{11} \mathrm{H}_{12} \mathrm{Cl}_{4} \mathrm{~N}_{2} \mathrm{O}_{4}$ \\
$\mathrm{C}$ & - & - & 34,28 & $34,92 \%$ \\
$\mathrm{H}$ & - & - & 3,72 & $3,17, "$ \\
$\mathrm{Cl}$ & - & 37,12 & - & $37,68, "$ \\
$\mathrm{~N}$ & 7,50 & - & - & $7,52, "$
\end{tabular}




\section{Ekstrand: Zur Kenntniss der Naphtoësäuren.}

Aus dem Folgenden wird ersichtlich, wie man die berechnete Formel wahrscheinlich zu deuten hat.

Mit Ammoniak übergossen, unterlag die Verbindung sofort einer merkwürdigen Veränderung, indem sie in rothe Nadeln verwandelt wurde, die in Wasser leicht löslich waren. Ein Zusatz von Essigsäure zum Wasser verminderte die Löslichkeit etwas. Die rothe Verbindung löste sich auch in starker Essigsäure beim Erwärmen und krystallisirte daraus in langen, hübschen, fast chromsäureähnlichen Nadeln. Der Schmelzpunkt konnte nicht bestimmt werden, schon etwas über $200^{\circ}$ trat Schwärzung und wahrscheinlich Zersetzung ein.

1. 0,2054 Grm. gaben 0,3504 Grm. $\mathrm{CO}_{2}$ und 0,0774 Grm. $\mathrm{H}_{2} \mathrm{O}$.

2. 0,2302 Grm. gaben bei $18,2^{\circ}$ und $767 \mathrm{Mm}$. 18,6 Ccm. N.

3. 0,2297 Grm. gaben 0,1100 Grm. AgCl.

4. 0,2057 Grm,, aus starker Essigsäure umkrystallisirt, gaben bei $15,4^{0}$ und $759 \mathrm{Mm}$. $16 \mathrm{Ccm}$. N.

\begin{tabular}{cccccc}
\multicolumn{3}{c}{ Gefunden: } & Berechnet für: \\
& 1. & 2. & 3. & 4. & $\mathrm{C}_{11} \mathrm{H}_{11} \mathrm{ClN}_{9} \mathrm{O}_{5}$ \\
$\mathrm{C}$ & 46,54 & - & - & - & $46,07 \%$ \\
$\mathrm{H}$ & $\mathbf{4 , 1 8}$ & - & - & - & $3,83 \%$ \\
$\mathrm{Cl}$ & - & - & 11,45 & - & $12,39 \%$ \\
$\mathrm{~N}$ & - & 9,60 & - & 9,24 & $9,77 \%$.
\end{tabular}

Der Chlorgehalt war also durch die Ammoniakbehandlung wesentlich erniedrigt, und der Gedanke lag jetzt nahe, dass die ursprüngliche Verbindung möglicherweise Salmiak enthielt; ich stellte daher eine neue Quantität dar in derselben Weise wie vorher, nur mit dem Unterschiede, dass etwas stärkerer Eisessig als Lösungsmittel angewandt wurde, was jedoch ohne Einfluss auf das Resultat zu sein schien, indem die jetzt erhaltene Verbindung in Aussehen und Eigenschaften der oben geschilderten ähnelte. Um etwa beigemengtes Chlorammonium zu entfernen, wurde das Krystallpulver, welches sich bei näherer Untersuchung als ein Gemenge von weissen und braunen Krystallen herausstellte, mit Wasser erwärmt, worin die weissen Kryställchen leicht löslich waren, und die filtrirte wässerige Lösung gab beim Abdampfen einen weissen, salzigen Rückstand, der aus fast reinem Chlorammonium bestand. Die in Wasser unlösliche Verbindung wurde 
behufs Reinigung in kochendem Eisessig gelöst und krystallisirte daraus beim Erkalten in langen, breiten, stumpfwinkelig zugespitzten Nadeln, die unter Aufblähen bei $259^{\circ}$ schmolzen. Sie waren ganz stickstofffrei.

1. $0,1731 \mathrm{Grm}$. gaben $0.3078 \mathrm{Grm} . \mathrm{CO}_{2}$ und $0,0310 \mathrm{Grm}$. $\mathrm{H}_{2} \mathrm{O}$.

2. $0,1579 \mathrm{Grm}$. gaben $0,1800 \mathrm{Grm}$. AgCl.

Gefunden:

$\begin{array}{ccc} & 1 . & 2 . \\ \mathrm{C} & +7,89 & - \\ \mathrm{H} & 1,96 & - \\ \mathrm{Cl} & - & 2 \times, 18\end{array}$

Berechnet für:

$$
\begin{gathered}
\mathrm{C}_{10} \mathrm{H}_{3} \mathrm{O}_{2} \mathrm{Cl}_{2} \mathrm{CO}_{z} \mathrm{H} \\
48,70 \% \\
1,47 \% \\
26,20 \% .
\end{gathered}
$$

Da der für die berechnete Formel allzu hohe Chlorgehalt vielleicht von einer Verunreinigung herrührte, wurde die Säure mit Sodalösung digerirt und das Filtrat mit Chlorwasserstofl'säure gefällt, wobei ein aus schwach violetten Nadeln bestehender Niederschlag ausfiel. Nach dem Umkrystallisiren aus Eisessig war die Verbindung der vorigen ganz gleich.

0,1053 Grm. gaben 0,1076 Grm. AgCl.

$$
\text { Cl Gefunden: } 25,28 \quad \text { Ber, f. } \mathrm{C}_{10} \mathrm{H}_{3} \mathrm{O}_{2} \mathrm{Cl}_{3} \mathrm{CO}_{2} \mathrm{H} \text { : }
$$

Durch die Behandlung mit Soda war also etwas Chlor eliminirt worden, es waren aber dennoch beinahe zwei Atome geblieben.

Bei einem anderen Versuche wurde die aus der Sodalösung ausgefällte Verbindung in Alkohol gelöst und krystallisirte daraus in breiten violett gefärbten Nadeln vom Schmelzpunkt $\mathbf{2 5 5 ^ { \circ }}$.

$0,1413 \mathrm{Grm}$. gaben 0,2474 Grm. $\mathrm{CO}_{3}$ und 0,0282 Grm. $\mathrm{H}_{2} \mathrm{O}$.

Gefunden:

$\mathrm{C}$

H
Ber. f. $\mathrm{C}_{10} \mathrm{H}_{3} \mathrm{O}_{2} \mathrm{Cl}_{2} \mathrm{CO}_{2} \mathrm{H}$ :

$48,70 \%$ 1,97 .

Wie man sieht, lassen die Analysenergebnisse etwas za wünschen übrig, was damit zusammenhängt, dass die hier zu besprechende Dichlornaphtochinoncarbonsäure theils das eine Chloratom leicht abgiebt, indem Sodalösung sogar dasselbe nicht intact lässt, theils von der Bereitung her ein wenig mit höheren Chlorderivaten vermischt zu sein scheint, welche nicht in einfacher Weise zu entfernen sind. 
Gegen Ammoniak verhielt sich die Dichlornaphtochinoncarbonsäure gerade so wie das ursprüngliche Chlorirungsprodukt; sie löste sich leicht darin, und die Lösung nahm, besonders beim Erwärmen, bald eine braune Farbe an und schied nach einiger Zeit einen zinnoberrothen Niederschlag von feinen Nadeln aus.

0,1350 Grm. dicses Niederschlages gaben 0,0690 Grm. Agcl.
C]
Gefunden: 12,62
Ber, f. $\mathrm{C}_{11} \mathrm{H}_{11} \mathrm{ClN}_{2} \mathrm{O}_{5}$ : $12,39 \%$.

Durch Ammoniak war daher der Säure ein Chloratom eutzogen, und statt dessen eine Hydroxylgruppe zugeführt worden, und in dem erhaltenen Produkte war wenigstens die Hälfte des Stickstoffes als Ammoniumgruppe vorhanden, weil es, gerade wie ein Ammoniumsalz, bei gelindem Erwärmen mit schwacher Natronlauge Ammoniak entwickelte. Das Salz unterlag keiner nennenswerthen Zersetzung durch Essigsäure, weil es aus sebr starker Säure beinahe unverändert krystallisirte (Analyse 4. S. 248). Durch Mineralsämen wurde es dagegen zersetzt, und Chlorwasserstoffsäure erzeugte einen aus feinen, rothen Nadeln bestehenden Niederschlag, der gegen $286^{\circ}$ schmoiz.

1. 0,1482 Grm. dieses Niederseblages, bei $100^{\prime \prime}$ getrocknet, gaben 0,0885 Grm. AgCl.

2. 0,1654 Grm. gaben bei $15^{\circ}$ and $758,2 \mathrm{Mm}$. $6,6 \mathrm{G} \cdot \mathrm{cm}$. N.

\begin{tabular}{cccc} 
& \multicolumn{2}{c}{ Gefunden: } & Berechnet für: \\
& 1. & 2. & $\mathrm{C}_{11} \mathrm{H}_{8} \mathrm{CINO}_{\mathrm{n}}$ \\
$\mathrm{Cl}$ & 14.27 & - & $13,17 \%$ \\
$\mathrm{~N}$ & & 5,04 & $5,19 \%$
\end{tabular}

Die Substanz war, weil aus Mutterlaugen ausgefällt, wabrscheinlich nicht ganz rein, aber die Analysen zeigen doch einerseits, dass eine $\mathrm{NH}_{3}$-Gruppe abgespalten worden, andererseits, dass die Verbindung wenigstens bei $100^{\circ}$ keinen Chlorwasserstoff enthielt und daher nicht als Chlorhydrat aufzufassen ist.

Wie oben bemerkt, wird dic Säure $\mathrm{O}_{10} \mathrm{H}_{3} \mathrm{O}_{2} \mathrm{Ol}_{2} \mathrm{CO}_{3} \mathrm{H}$ von Salzlösung fast unverändert aufgenommen, während Ammoniak derselben ein Chloratom entzieht; es war von vornherein anzunehmen, dass auch die fixen Alkalien sich wie 
Ammoniak verhalten, was durch den Versuch bestätigt wurde. Die Säure wurde mit alkoholischer Kalilauge erwärmt, wobei ein rother, flockiger Niederschlag entstand, der in Wasser vollständig löslich war; die mit Chlorwasserstoff angesäuerte Lösung setzte zwar keinen Niederschlag ab; nach Abdampfen krystallisirte aber eine Substanz, die, mit Wasser gewaschen und aus Eisessig umkrystallisirt, in gelbrothen, harten Blättern erhalten wurde, die gegen $240^{\circ}$ schmolzen und keinen Glührückstand hinterliessen.

$$
\begin{gathered}
\text { 0,0737 Grm. gaben 0,0380 Grm. AgCl. } \\
\begin{array}{ll}
\text { Gefunden: } & \text { Ber. f. } \mathrm{C}_{10} \mathrm{H}_{3} \mathrm{O}_{2} \mathrm{OHCl} . \mathrm{CO}_{2} \mathrm{H} \text { : } \\
\text { Cl } 12,76 \% & 14,05 \% .
\end{array}
\end{gathered}
$$

Diese Analyse, obwohl mit zu geringer Substanzmenge ausgeführt, beweist dennoch, dass auch durch alkoholisches Kali die Ersetzung des einen Chloratomes mit Hydroxyl bewerkstelligt werden kann, wahrscheinlich wird sich wässeriges Kali ebenso verhalten.

Monochloroxynaphtochinoncarbonsäure wurde auch aus dem oben genannten rothen Ammoniakderivate, $\mathrm{C}_{11} \mathrm{H}_{8} \mathrm{ClNO}_{5}$, erhalten, indem dieses mit schwacher Natronläuge bis zum Aufhören der Ammoniakentwickelung erhitzt wurde; auf Zusatz von Chlorwasserstoffsäure schied sich dann allmählich eine Masse von gelbrothen Nadeln ab, die in Alkohol leicht löslich, in kaltem Wasser aber schwer löslich waren. Bei langsamer Krystallisation aus Wasser wurde die Verbindung in harten, orangegelben, rhombischen Tafeln erhalten, die unter Aufblähen bei $246^{\circ}$ schmolzen. Sie waren stickstofffrei.

$$
\begin{aligned}
& \text { 0,1769 Grm. gaben 0,3410 Grm. } \mathrm{CO}_{2} \text { und 0,0427 Grm. } \mathrm{H}_{2} \mathrm{O} \text {. } \\
& \begin{array}{ccc} 
& \text { Gefunden: } & \text { Ber. f. } \mathrm{C}_{10} \mathrm{H}_{3} \mathrm{O}_{2} \text { OHClCO}, \mathrm{H}: \\
\mathrm{C} & 52,57 & 52,28 \% \\
\mathrm{H} & 2,66 & 1,98, .
\end{array}
\end{aligned}
$$

Aus diesen Verhältnissen lässt sich nun der Verlauf beim Einwirken des Ammoniaks auf Dichlornaphtochinoncarbonsäure in einfacher Weise erklären; es muss nämlich eine Hydroxylgruppe das eine Chloratom substituirt haben, 
und gleichzeitig ein Diammoniumsalz nach folgendem Schema entstanden sein:

$$
\begin{gathered}
\mathrm{C}_{10} \mathrm{H}_{3} \mathrm{O}_{2} \mathrm{ClCO}_{2} \mathrm{H}+3 \mathrm{NH}_{2}+\mathrm{H}_{2} \mathrm{O}=\mathrm{NH}_{4} \mathrm{Cl}+\mathrm{C}_{11} \mathrm{H}_{11} \mathrm{ClN}_{2} \mathrm{O}_{5}= \\
\mathrm{NH}_{4} \mathrm{Cl}+\mathrm{C}_{10} \mathrm{H}_{3} \mathrm{O}_{2} \mathrm{ONH}_{4} \mathrm{ClCO}_{2} \mathrm{NH}_{4} .
\end{gathered}
$$

Dieses Ammoniumsalz, welches nicht oder nur wenig von Essigsäure angegriffen wird, zersetzt sich in Berührung mit stärkeren Säuren so, dass das saure Salz

$$
\mathrm{O}_{11} \mathrm{H}_{8} \mathrm{ClNO}_{6}=\mathrm{C}_{10} \mathrm{H}_{3} \mathrm{O}_{2} \mathrm{ONH}_{4} \mathrm{ClCO}_{2} \mathrm{H}
$$

entsteht. Dass man es hier nicht mit einem Amide zu thun hat, geht aus der Leichtigkeit hervor, womit das Ammoniak von schwacher Natronlauge ausgetrieben wird, obwohl das Salz andererseits durch seine Beständigkeit gegen Chlorwasserstoffsäure den Amiden ähnlich ist.

Zusammenfassung. Bei der Einwirkung von Chlor auf eine Eisessiglösung der Amido-c $c$-naphtoësäure $\left(1,4^{\prime}\right)$ wird die Amidogruppe leicht ausgetrieben, und weil dabei sowohl Dichlornaphtochinoncarbonsäure wie Chlorammonium entstehen, muss die Reaktion, wenigstens der Hauptsache nach, in folgender Weise gedacht werden:

$\mathrm{C}_{10} \mathrm{H}_{8} \mathrm{NH}_{2} \mathrm{CO}_{2} \mathrm{H}+8 \mathrm{Cl}+2 \mathrm{H}_{2} \mathrm{O}=\mathrm{C}_{10} \mathrm{H}_{3} \mathrm{O}_{2} \mathrm{Cl}_{2} \mathrm{CO}_{2} \mathrm{H}+\mathrm{NH}_{4} \mathrm{Cl}+5 \mathrm{HCl}$.

Es entstehen auch nebenbei andere, theilweise schmierige Produkte, die aber nicht untersucht worden sind.

Die aus der Eisessiglösung abgeschiedene Krystallmasse scheint ziemlich constant die Zusammensetzung:

$$
\mathrm{C}_{11} \mathrm{H}_{12} \mathrm{Cl}_{4} \mathrm{~N}_{2} \mathrm{O}_{4}=\mathrm{C}_{10} \mathrm{H}_{3} \mathrm{O}_{2} \mathrm{Cl}_{2} \mathrm{CO}_{2} \mathrm{H}+2 \mathrm{NH}_{4} \mathrm{Cl}
$$

zu haben, wahrscheinlich aus dem Grunde, dass von dem Chlorammonium, weil schwer löslicher in Eisessig, verhältnissmässig mehr auskrystallisirt, als von der Säure, wovon in der essigsauren Mutterlauge noch viel enthalten war.

Wie ersichtlich, fordert die eben geschilderte Reaktion die Gegenwart von Wasser, und ich habe noch nicht prüfen können, wie der Chlorirungsprocess in absolut wasserfreiem Eisessig verläuft; wahrscheinlich wird das Resultat ein anderes sein.

Die erhaitene Dichlornaphtochinoncarbonsäure verliert lescht das eine Chloratom schon beim Uebergiessen mit gewöhnlicher Ammoniakflussigkeit und geht dabei in die Mono- 
chloroxynaphtochinoncarbonsäure über, deren neutrales Ammoniumsalz: $\mathrm{C}_{10} \mathrm{H}_{3} \mathrm{O}_{2} \mathrm{ONH}_{4} \mathrm{ClCO}_{2} \mathrm{NH}_{4}$ hübsche zinnoberrothe Nadeln bildet.

Es mag noch hinzugefügt werden, dass die Ammoniakderivate der Chloroxynaphtochinoncarbonsäure sich in Alkalilauge mit tief purpurrother Farbe lösen, welche jedoch bald ins Braune übergeht.

$\mathrm{Ob}$ die obigen Verbindungen als Derivate des $\alpha$-oder des $\beta$-Naphtochinons aufzufassen sind, lässt sich aus ihren bisher bekannten Verhältnissen nicht entscheiden, ich kann jedoch nicht umhin, zu bemerken, dass sie etwas an das Dichlor-o-naphtochinon erinnern, indem dasselbe gleichfalls unter Einwirkung von Alkalien in Monochloroxynaphtochinon übergeht $\left(G^{\prime r a e b e}{ }^{1}\right)$. Leider reichte das Material für weitere Versuche nicht aus.

Wie aus der Peri-amido- $\alpha$-naphtoësäure vermittelst des Naphtostyrilchinons verschiedene Derivate der $\beta$-Naphtochinoncarbonsäure sich werden darstellen lassen (s. S. 185), so bietet vielleicht die Amido- $c$-naphtoësäure $\left(1,4^{\prime}\right)$ ein geeignetes Material für das Studium der $a$-Naphtochinoncarbonsäure und ihrer Derivate.

\section{Monochlor-mononitro- $\alpha$-naphtoësäure rom} Schmelzp. $227^{\circ}$.

Die Perichlor- $\boldsymbol{c}$-naphtoësäure $\left(1,1^{\prime}\right)$ wurde unter Kühlung mit rother, rauchender Salpetersäure uabergossen, und das erhaltene Produkt mit Wasser versetzt, wobei es in einezähe Masse überging. Beim Digeriren mit Sodalösung blieb ein Theil davon ungelöst zurück; aus dem Filtrate schied sich auf Zusatz von Chlorwasserstoffsäure ein gelber krystallinischer Niederschlag ab, der in Alkohol leicht löslich war und aus der alkoholischen Lösung in zweierlei Krystallen, wie es schien, nämlich theils in rhombischen Blättern, theils in Nadeln krystallisirte. Auch nach erneutem Lösen und langsamem Krystallisirenlassen wurden dieselben in zwei Krystall-

1) Ann. Chem. 149, 3. 
254 Fkstrand: Zur Kenntniss der Naphtoësäuren.

formen erhalten, beide zeigten aber denselben Schmelzp. $226^{\circ}$, und waren daher wahrscheinlich identisch; noch einmal wurde das Umkrystallisiren wiederholt, und die Verbindung schoss dann in breiten Prismen vom Schmelzp. $227^{\circ}$ an.

$0,1738 \mathrm{Grm}$. gaben bei $13,6^{\circ}$ und $749 \mathrm{Mm}$. 8,6 Ccm. N.

\begin{tabular}{|c|c|}
\hline Gefunden: & Ber. f. $\mathrm{C}_{10} \mathrm{H}_{5} \mathrm{ClNO}_{2} \mathrm{CO}_{2} \mathrm{H}$ : \\
\hline 5,83 & $5,56 \%$ \\
\hline
\end{tabular}

Der Aethyläther, aus dem Silbersalze und Jodäthyl dargestellt, krystallisirte aus Alkohol in weissgelben Schuppen vom Schmelzp. $84^{\circ}$.

$0,1825 \mathrm{Grm}$. gaben $0,3712 \mathrm{Grm} . \mathrm{CO}_{2}$ und 0,0641 Grm. $\mathrm{H}_{2} \mathrm{O}$.

$\begin{array}{ccc} & \text { Gefunden: } & \text { Ber. f. } \mathrm{C}_{10} \mathrm{H}_{5} \mathrm{ClNO}_{2} \mathrm{CO}_{2} \mathrm{C}_{2} \mathrm{H}_{5}: \\ \mathrm{C} & 55,47 & 55,81 \% \\ \mathrm{H} & 3,88 & 3,57 \% .\end{array}$

Chloramido- $\iota-n a p h$ toësäure.

Die vorstehende Nitrochlornaphtoësäure wurde, wie gewöhnlich, in ammoniakalischer Lösung mit Ferrosulfat reducirt, das Filtrat mit Essigsäure gefällt, und der Niederschlag in Alkohol gelöst. Die Amidosäure krystallisirte daraus in hübschen, farblosen Nadeln, die schon bei $210^{\circ}$ zu schmelzen anfingen; dabei schien jedoch eine Veränderung eingetreten zu sein, indem die Verbindung nachher erst über $285^{\circ}$ vollständig geschmolzen war.

$0,2171 \mathrm{Grm}$. gaben bei $14,4^{\circ}$ and $757,6 \mathrm{Mm} .11,6 \mathrm{Ccm}, \mathrm{N}$.

$$
\begin{aligned}
& \text { Gefunden: Ber. f. } \mathrm{C}_{10} \mathrm{H}_{5} \mathrm{CINH}_{2} \mathrm{CO}_{2} \mathrm{H} \text { : } \\
& \mathrm{N} \quad 6,33 \quad 6,32 \% \text {. }
\end{aligned}
$$

Das Chlorhydrat, durch Einwirkung von verdüinter Chlorwasserstoffsäure auf die Amidosäure erhalten, war ziemlich leicht löslich in Wasser und krystallisirte in langen, harten Nadeln, besonders leicht aus einer mit Chlorwasserstoff stark angesäuerten Lösung.

Es mag hervorgehoben werden, dass der Unterschied bezüglich des Schmelzpunktes zwischen der hier in Rede stehenden Nitrochlor- $\alpha$-naphtoësäure und der oben (S. 170) besprochenen Isomeren ganz gering ist, wohingegen die Schmelzpunkte der betreffenden Aethyläther sich bedeutend 
mehr von einander unterscheiden. Auch in einer anderen Beziehung sind die beiden Nitrochlorderivate verschieden: die bei $224^{\circ}-225^{\circ}$ schmelzende Säure giebt nämlich ein Amidoderivat, das beim Erhitzen mit Alkohol leicht in das indifferente Monochlornaphtostyril übergeht, während das ans der bei $227^{\circ}$ schmelzenden Säure erhaltene Amidoderivat beim Kochen mit Alkohol unverändert bleibt.

Dichlor-mononitro- $\alpha-n a p h$ toësäure.

Die Dichlor - $\alpha$-naphtoësäure $\left(\mathrm{CO}_{3} \mathrm{H}, \mathrm{Cl}, \mathrm{Cl}: 1^{\prime}, 1^{\prime}, 4^{\prime}\right)$ wurde in rother rauchender Salpetersäure gelöst, und die Lösung ein wenig auf dem Wasserbade erwärmt. Das gebildete Produkt war in der salpetersauren Mutterlauge sehr leicht löslich und schied sich auf Zusatz von Wasser als ein Harz aus. Beim Digeriren desselben mit Ammoniak blieb ein Theil ungelöst, und aus dem Filtrate wurde die Nitrosäure mit Chlorwasserstoffsüure niedergeschlagen. Der Niederschlag war auch jetzt eine zähe Masse, die mit Wasser gewaschen und dann in ganz wenig Eisessig gelöst wurde. Nachdem das Lösungsmittel fast vollständig verdunstet war, setzte sich eine Krystallkruste $a b$, die gepresst und mit etwas Eisessig gewaschen wurde. Der so gereinigte Körper war hellgelb und schmolz gegen $165^{\circ}$. Wegen seiner grossen Leichtlöslichkeit sowohl in Alkohol wie in Fisessig konnte er durch Umkrystallisiren nur schwer gereinigt werden; die Lösungen trockneten zuweilen fast ein.

0,1748 Grm. gaben bei $17^{\circ}$ und $760,5 \mathrm{Mm}, 7,6 \mathrm{Ccm}$. N.

$$
\begin{aligned}
& \text { Gefunden: } \quad \text { Ber. f. } \mathrm{C}_{10} \mathrm{H}_{4} \mathrm{Cl}_{2} \mathrm{NO}_{2} \mathrm{CO}_{3} \mathrm{H} \text { : } \\
& \mathrm{N} \quad 5,14 \quad 4,89 \% \text {. }
\end{aligned}
$$

Aehnlich wie eine der weiter unten zu beschreibenden Trinitro- $\alpha$-naphtoësäuren, hatte auch diese Nitrodichlornaphtoësäure einen intensiv bitteren Geschmack, so dass schon die geringste Spur davon einen lebhaften Ekel hervorrief.

Es ist mir nicht gelungen, aus dieser Säure einen krystallisirenden Aethyläther darzustellen. Aus der alkoholischen Lösung setzte er sich wiederholt zähe und klebrig ab. 
Dinitroderivate der $\alpha$-Naphtoësäure

Um solche zu erhalten, wurde die $\alpha$-Naphtoësäure in kleinen Portionen zu einem Ueberschuss von rother rauchender Salpetersäure gesetzt, und die durch die Reaction hervorgebrachte Erwärmung durch Abkühlen gemässigt. Die Reaction war übrigens sehr heftig und von Gasentwicklung begleitet. Um alles zu lösen, wurde am Ende etwas erwärmt, und die klare Lösung nachher der Ruhe überlassen. Nach einigen Tagen hatte sich ein krystallinisches Pulver abgesetzt, welches von der Mutterlauge befreit, mit Sodalösung digerirt wurde. Dabei blieb ein indifferenter Körper zurück, dessen weiter unten gedacht werden soll. Die Lösung wurde mit Chlorwasserstoffsäure gefällt, und der Niederschlag aus Alkohol umkrystallisirt. Der so erhaltene Körper war jedoch kein einheitlicher, denn trotz wiederholtem Umkrystallisiren aus Alkohol zeigte der Schmelzpunkt nicht genügende Schärfe; wahrscheinlich lag ein Gemenge von zwei oder mehreren Dinitrosäuren vor; die Zusammensetzung war nämlich die einer Dinitronaphtoësäure. Aus dem Gemenge konnte nur die folgende Säure rein erhalten werden, und sie war jedenfalls auch das Hauptprodukt.

Dinitro- $\alpha-n$ a phtoësäure vom Schmelzp. $265^{\circ}$.

Auf obige Weise gelang es nur schwer, eine reine Säure zu erzielen. Durch Ueberführung in den Aethyläther und Wiedergewinnung der Säure aus demselben konnte die Säure reiner erhalten werden. Der Schmelzpunkt der so gereinigten Substanz lag bei $265^{\circ}$; sie krystallisirte aus Alkohol in kleinen, gelblichweissen Nadeln, war leicht löslich in warmem Alkohol und Eisessig, schwer löslich dagegen in Aether und Benzol, sie war auch etwas löslich in heissem Wasser und liess sich in gelben Nädelchen sublimiren.

1. 0,1980 Grm. gaben 0,3630 Grm. $\mathrm{CO}_{2}$ und 0,0480 Grm. $\mathrm{H}_{3} \mathrm{O}$.

2. 0,2798 Grm. gaben bei $14,5^{\circ}$ und $758 \mathrm{Mm}$. $26 \mathrm{Cem}$. N.

\begin{tabular}{cccc} 
& \multicolumn{2}{c}{ Gefunden: } & Berechnet für: \\
& 1. & 2. & $\mathrm{C}_{10} \mathrm{H}_{5} \mathrm{NO}_{2} \mathrm{CO}_{2} \mathrm{H}$ \\
$\mathrm{C}$ & 50,00 & - & $50,30 \%$ \\
$\mathrm{H}$ & 2,67 & - & $2,29 \%$ \\
$\mathrm{~N}$ & - & 10,57 & $10,68 \%$
\end{tabular}


Leichter und reiner wurde diese Dinitro- $c$-naphtoësäure aus der Mononitrosäure rom Schmelzp. $239^{\circ}$ erhalten. Wenn nämlich diese Säure mit rother rauchender Salpetersäure auf dem Wasserbade gelinde erhitzt wurde, so trat bald Lösung ein, und, wenn nicht zu viel Salpetersäure angewandt war, d. h. wenn die Lösung einigermassen concentrirt war, setzte sich bald eine Krystallmasse ab, die nach Absaugen der Mutterlauge mit Ammoniak digerirt wurde, um indifferente Körper zu entfernen. Das Filtrat, mit Chlorwasserstoffsäure gefällt, gab einen Niederschlag, der aus Alkohol in weissgelben Nadeln vom Schmelzp. $265^{\circ}$ krystallisirte. Aus $40 \mathrm{Grm}$. der Mononitro- $\alpha$-naphtoësäure wurden in dieser Weise gegen $20 \mathrm{Grm}$. der Dinitrosäure erhalten. Bei der directen Darstellung aus der $\alpha$-Naphtoësäure war die Ausbeute dagegen sehr schlecht.

Der Aethyläther konnte sowohl aus dem Silbersalze mit Jodäthyl wie auch durch Sättigen der alkoholischen Lösung der Säure mit Chlorwasserstoffgas erhalten werden und krystallisirte aus Alkohol in feinen Nadeln vom Schmelzp. 143".

0,2088 Grm. gaben 0,4102 Grm. $\mathrm{CO}_{2}$ und 0,0735 Grm. $\mathrm{H}_{2} \mathrm{O}$.

$\begin{array}{ccc} & \text { Gefunden: } & \text { Ber. f. } \mathrm{C}_{10} \mathrm{H}_{5}\left(\mathrm{NO}_{3}\right)_{2} \mathrm{CO}_{2} \mathrm{C}_{2} \mathrm{H}_{5} \text { : } \\ \mathrm{C} & 53,59 & 53,79 \% \\ \mathrm{H} & \mathbf{3 , 9 0} & \mathbf{3 , 4 5},\end{array}$

Das Natriumsalz, $\mathrm{C}_{10} \mathrm{H}_{5}\left(\mathrm{NO}_{2}\right)_{2} \mathrm{CO}_{2} \mathrm{Na}+6 \mathrm{H}_{2} \mathrm{O}$, bildet lange, prismatische, gelbe Nadeln, ist sehr leicht löslich, auch in kaltem Wasser.

0,3432 Grm., getrocknet zwischen Löschpapier, verloren bei $140^{\circ}$ $0,0937 \mathrm{Grm} . \mathrm{H}_{2} \mathrm{O}=27,30 \%$; ber. $27,55 \%$; der Rückstand, $0,2495 \mathrm{Grm}$., gab 0,0610 Grm. $\mathrm{Na}_{2} \mathrm{SO}_{4}=7,92 \% \mathrm{Na} ;$ ber. $8,09 \%$.

Das Calciumsalz, $\left(\mathrm{C}_{10} \mathrm{H}_{5}\left(\mathrm{NO}_{2}\right)_{2} \mathrm{CO}_{2}\right)_{2} \mathrm{Ca}+3 \mathrm{H}_{2} \mathrm{O}$, krystallisirt in weichen Nadeln, die in warmem Wasser ziemlich leicht löslich sind, aber bei gewöhnlicher Temperatur gegen 138 Thle. zur Lösung erfordern.

1. 27,5013 Grm. einer bei gewöhnlicher 'Temperatur gesättigten Lösung gaben 0,1975 Grm. bei $95^{\circ}$ getrockneten Rückstand.

2. 0,3827 Grm., zwisehen Filtrirpapier gepresst und im Exsiccator getrocknet, verloren bei $140^{\circ} 0,0336 \mathrm{Grm} . \mathrm{H}_{2} \mathrm{O}=8,78 \%$; ber. $8,76 \%_{0} \mathrm{H}_{2} \mathrm{O}$.

3. $0,2845 \mathrm{Grm}$. des wasserfieien Salzes gaben $0,0680 \mathrm{Grm} . \mathrm{CaSO}_{4}$ $=7,03 \%$ Ca; ber. $7,11 \%$ Ca.

Journal f. prakt. Chemie [2] Bd, $3 \mathrm{~s}$. 
Das Baryumsalz, $\left(\mathrm{C}_{10} \mathrm{~B}_{5}\left(\mathrm{NO}_{2}\right)_{2} \mathrm{CO}_{2}\right)_{2} \mathrm{Ba}+21 / 2 \mathrm{H}_{2} \mathrm{O}$, ist leicht löslich in warmem Wasser und krystallisirt in körnigen Aggregaten von kleinen, gelben Prismen.

1. $0,5432 \mathrm{Grm}$, zwischen Löschpapier getrocknet, verloren bei $135^{\circ} 0,0330 \mathrm{Grm}$. $\mathrm{H}_{2} \mathrm{O}=6,07 \%$; ber.: $6,39 \% \mathrm{H}_{2} \mathrm{O}$.

2. $0,2829 \mathrm{Grm}$. des wasserfreien Salzes gaben 0,0998 $\mathrm{BaSO}_{4}=$ $20,74 \% \mathrm{Ba}$; her. $20,78^{\circ}$ Ba.

Wie oben erwähnt, wurde bei der Einwirkung von rother, rauchender Salpetersäure auf $\alpha$-Naphtoësäure auch ein indifferenter Körper erbalten, der besonders in der salpetersauren Mutterlauge von der Dinitrosäure enthalten war und durch $W$ asser daraus gefällt wurde. Eine Analyse des Produktes gab Zahlen, die ziemlich gut für das Dinitronaphtalin passten, und beim Umkrystallisiren aus Alkohol konnte es in zwei Verbindungen zerlegt werden, von denen die eine mit dem Schmelzp. $155^{\circ}-160^{\circ}$ in Alkohol leicht löslich, die andere mit dem Schmelzp. 170" darin schwer löslich war. Diese letztere, die den weitaus überwiegenden Antheil des Produktes ausmachte, war das sogenannte $\beta$ Dinitronaphtalin, das, wie schon früher erwähnt ist, leicht aus der Mononitro- $\alpha$-naptoësäure vom Schmelzp. $215^{\circ}$ beim Behandeln mit Salpetersäure erhalten wird. Man kann sich daher den Vorgang bei der directen Nitrirung der $\alpha$-Naphtoësäure mit rauchender Salpetersäure ganz einfach so vorstellen, dass in ersten Stadium die beiden Mononitronaphtoësäuren von den Schmelzpunkten $239^{\circ}$ und $215^{\circ}$ gebildet werden, im zweiten Stadium dagegen aus der ersteren die "Dinitrosäure entsteht, die andere aber in das c-Dinitronaphtalin übergeht.

\section{Diazinnaph toësäure.}

Wenn die ammoniakalische Lösung der obigen Dinitro$u$-naphtoësäure vom Schmelzp. $265^{\circ}$ mit Schwefelwasserstoff übersättigt wurde, trat eine intensiv violette Färbung ein. Nachdem der überschïssige Schwefelwasserstoff durch Erhitzen auf dem Wasserbade entfernt worden war. wurde Wasser zugesetzt. und die Lösung mehrere Tage der Ruhe 
überlassen, damit der aufgeschlämmte, äusserst fein vertheilte Schwefel zu Boden sinken konnte. Die dekantirte und filtrirte Lösung wurde mit Essigsäure gefällt, wobei sich ein tief blauvioletter Niederschlag langsam absetzte. Dieser Niederschlag war in den gebräuchlichen Lösungsmitteln wie Alkohol, Aether, Aceton, Eisessig, Benzol und Toluol nur unbedeutend löslich und schied sich aus Alkohol und Eisessig in violetten, unkrystallinischen Flocken aus. Zudem liess sich die Verbindung weder sublimiren noch schmelzen; in einem Proberöhrchen erhitzt, erlitt sie sogar bei der Rothgluth keine sichtbare Veränderung. Unter solchen Umständen war die Reinigung der Substanz mit grossen Schwierigkeiten verbunden. Um jedoch womöglich Amidosäuren und unveränderte Dinitrosäure zu entfernen, habe ich die feingepulverte Substanz zuerst mit Chlorwasserstoffsäure und dann mit Alkohol lange gekocht. Der Rückstand wurde dann von Neuem in Ammoniak gelöst und die filtrirte Lösung mit Essigsäure gefällt. Es zeigte sich, dass die Verbindung trotz aller Reinigungsversuche etwas Schwefel enthielt, und, obwohl es nicht wahrscheinlich ist, dass Schwefel in das Molekül eingeht, hat es mir doch nicht gelingen wollen, denselben zu entfernen, sei es durch wiederholtes Lösen in Ammoniak und Ausfällen mit Essigsäure, sei es durch Kochen der getrockneten Verbindung mit Schwefelkohlenstoff. Nach dem Trocknen nahm die Substanz einen leb. haften braunen Bronceglanz an.

1. 0,2083 Grm. gaben bei $13,2^{\circ}$ und $771,4 \mathrm{Mm}$. 22,2 Gem. N.

2. $0,1945 \mathrm{Grm}$. gaben 0,4471 Grm. $\mathrm{CO}_{2}$ und $0,0709 \mathrm{H}_{2} \mathrm{O}$.

3. $0,1816 \mathrm{Grm}$. gaben bei $15,8^{\circ}$ und $757,2 \mathrm{Mm}$. $20 \mathrm{Cem}$. N.

4. 0,1691 Grm. gaben bei $11,4^{\circ}$ und $762,8 \mathrm{Mm}$. 19,1 Cem. N.

5. $0,2125 \mathrm{Grm}$. gaben $0,4894 \mathrm{Grm} . \mathrm{CO}_{2}$ und $0,0762 \mathrm{Grm} . \mathrm{H}_{2} \mathrm{O}$.

6. 0,2132 Grm. gaben $0,4958 \mathrm{Grm}$. $\mathrm{CO}_{2}$ und $0,0802 \mathrm{Grm} . \mathrm{H}_{2} \mathrm{O}$.

7. 0,1543 Grm. gaben, mit Soda und Kaliumchlorat verbrannt, 0,0597 Grm. $\mathrm{BaSO}_{4}$.

8. 0,1929 Grm. gaben 0.0732 Grm. $\mathrm{BaSO}_{4}$.

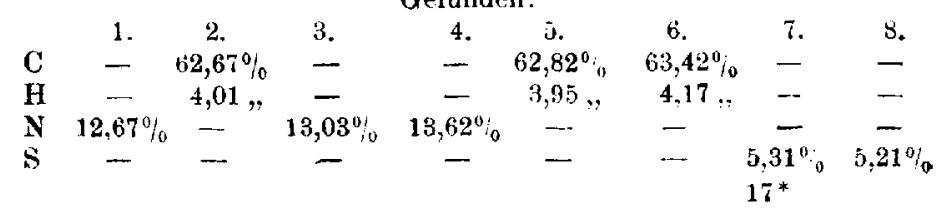


Die Verbindung war sehr schwer verbrennlich und wurde daher mit Bleichromat im Sauerstoffstrome verbrannt; zur Analyse 6 wurde sogar eine Mischung von Kaliumdichromat und Bleichromat genommen. Die zur Analyse 8 angewandte Substanz war mit Schwefelkohlenstoff ausgekocht. Die gefundenen Zahlen setzten eine complicirte Zusammensetzung voraus, hauptsächlich wegen der Gegenwart des Schwefels, und eine Formel, die einigermassen den Analysen entspricht, wäre die folgende: $\mathrm{C}_{33} \mathrm{H}_{18} \mathrm{~N}_{6} \mathrm{SO}_{6}$, woraus berechnet werden :

$$
\begin{array}{lr}
\mathrm{C} & 63,25 \% \\
\mathrm{H} & 2,87 \% \\
\mathrm{~N} & 13,41 \% \\
\mathrm{~S} & 5,11 \% \\
\mathrm{O} & 15,36 \% \\
\hline & 100,00 \%
\end{array}
$$

Mit Ausschluss des Schwefels dagegen wird die Formed $\mathrm{C}_{11} \mathrm{H}_{6} \mathrm{~N}_{2} \mathrm{O}_{2}$ erhalten, die auch $\mathrm{CO}_{2} \mathrm{H} . \mathrm{C}_{10} \mathrm{H}_{5}<{ }_{\mathrm{N}}^{\mathrm{N}}$ geschrieben werden kann. Wird aber der Schwefel als ein integrirender Bestandtheil der Substanz angenommen, so ist es wohl am einfachsten, in dem bezüglichen Sulfid der Diazinnaph to ësäure drei Gruppen $\mathrm{CO}_{2} \mathrm{H} . \mathrm{C}_{10} \mathrm{H}_{6} \mathbb{N}_{-}^{\mathrm{N}-}$ durch ein Atom Schwefel zusammengehalten zu denken, etwa in folgender Weise :

$$
\left\{\begin{array}{l}
\mathrm{N}>\mathrm{C}_{10} \mathrm{H}_{5} \mathrm{CO}_{2} \mathrm{H} \\
\mathbf{N}>\mathrm{C}_{10} \mathrm{H}_{5} \mathrm{CO}_{2} \mathrm{H} .
\end{array}\right.
$$

Wie dem auch sei, so hat doch durch den Schwefelwasserstoff eine Reduction der beiden Nitrogruppen stattgefunden, und die Leichtigkeit, mit welcher dies geschieht, muss am so mehr auffallen, wenn ich daran erinnere, dass z. B. die Mononitro- $\alpha$-naphtoësäure von Schmelzp. $215^{\circ}$ durch Schwefelwasserstoff' in ammoniakalischer Lösung ganz und gar 
nicht verändert wird; es kann daher keiue der Nitrogruppen in benachbarter $\alpha$-Stellung zur Carboxylgruppe stehen, vielmehr deuten die Reductionsverhältnisse darauf, dass die beiden Nitrogruppen selbst benachbarte $\alpha$-Stellungen einnehmen; es hat sich nämlich oft gezeigt, dass Substituenten in diesen Stellungen gern aufeinander zur Bildung eines fünfgliedrigen Ringes reagiren, Ein gleich unten $\mathrm{zu}$ besprechender Reductionsversuch hat diese Vermuthung rollständig bestätigt.

Die Diazinnaphtoësäure, sei sie nun schwefelhaltig oder nicht, löst sich mit blauvioletter Earbe in Alkalien und Alkalicarbonaten, aber es konnten keine krystallisirenden Salze aus diesen Lösungen erhalten werden, denn beim Eindampfen trockneten sie allmählich zu einer Art Lack ein. von demselben Bronceglanz wie die Säure selbst. Andere Metallsalze der Säure bildeten amorphe, blauschwarze Niederschläge. Beim Kochen mit Zinn und Chlorwasserstoffsäure zeigte die Säure keine sichtbare Veränderung. In concentrirter Schwefelsäure löste sie sich ein wenig mit indigblauer Farbe, auf Zusatz von Wasser fiel sie aber wieder aus, und die Lösung wurde entfärbt.

Auch andere Reductionsmittel gaben mit der Dinitro$\alpha$-naphtoësäure ähnliche Produkte. So habe ich etwas mehr als die berechnete Menge in Kalihydrat gelöstes Zinnchlorür auf eine alkalische Lösung der Dinitrosäure einwirken lassen; schon bei gewöhnlicher Temperatur wurde die Lösung blaugrün, und die Farbe trat beim Erhitzen intensiver hervor. Nach ein paar Stunden fortgesetztem Erwärmen auf dem Wasserbade wurde, um das Zinnoxyd zu entfernen, Kohlendicxyd eingeleitet; weil aber dadurch die Flüssigkeit fast schleimige Consistenz annahm, wurde Essigsäure zugesetzt, wonach ein fast schwarzer Niederschlag langsam ausfiel. Nach dem Coliren und Waschen, soweit es die Beschaffenheit gestattete, wurde der Niederschlag in schwachem Ammoniak gelöst, und das Filtrat wieder mit Essigsäure gefällt. Der so erhaltene Niederschlag wurde in Leinwand gepresst, bei $110^{\circ}$ getrocknet und in ein feines Pulver verwandelt, das wiederholt mit starker Chlorwasserstoffsäure ausgekocht wurde, 
um anorganische Bestandtheile zu entfernen; der Rückstand wurde schliesslich in Ammoniak gelöst und noch einmal derselben Behandlung unterworfen. Trotz dieser Reinigungsversuche gab das Produkt doch immer etwas Asche beim Verbremnen. Die Verbindung war getrocknet ein schwarzblaues Pulver, unlöslich in Alkohol und Eisessig; sie war auch unschmelzbar und ähnelte übrigens ganz dem nit Schwefelwasserstoff erhaltenen Reductionsprodukte; nur war die Farbe mohr dunkel. Weil ich kein Mittel zum Reinigen der Substanz hatte, musste ich auf die weitere Untersuchung verzichten und mich mit einigen Analysen begnügen, um den Verlauf bei der Reduction mit Zinnoxydulkalium zu erfahren.

1. 0,1919 Grm. gaben 0,4512 Grm. $\mathrm{CO}_{2}$ und 0,0712 Grm. $\mathrm{H}_{2} \mathrm{O}$.

2. $\quad\left(1,1816\right.$ Grm. gaben bei $15,8^{\circ}$ and $757,2 \mathrm{Mm}$. $211 \mathrm{C} \cdot \mathrm{m}$. N.

\begin{tabular}{|c|c|c|c|}
\hline \multicolumn{3}{|c|}{ Gefunden: } & \multirow{2}{*}{ Ber, für $\mathrm{CO}_{2} \mathrm{H} \cdot \mathrm{O}_{1,} \mathrm{H}_{5}$} \\
\hline & 1. & $\stackrel{2}{2}$ & \\
\hline $\mathrm{C}$ & 64.15 & - & $66.65 \%$ \\
\hline $\mathrm{H}$ & 4,11 & - & 3,083 \\
\hline $\mathbf{N}$ & - & 13,05 & $14,1+$, \\
\hline
\end{tabular}

Diese gefundenen Zahlen stimmen zwar nicht auf die berechnete Formel, aber in Betracht des Aschengehaltes und der Schwierigkeit einer Reinigung muss doch eine gewisse Wahrscheinlichkeit der angeführten Formel eingeräumt werden, und der Verlauf des Reductionsprocesses unter Anwendung sowohl von Zinnoxydulkalium wie von Schwefelwasserstoff in der Hauptsache derselbe sein, abwohl im letzteren Falle die Bildung eines schwefelhaltigen Produktes nicht ausgeschlossen zu sein scheint.

Diamidonaphtalin. Die Dinitro-re-naphtoësäure vom Schmelzp. $265^{\circ}$ wurde mit Zinn und starker Chlorwasserstoffsäure erhitzt, wobei bald eine heftige Reaction eintrat und ein gelbes Pulver abgeschieden wurde, welches unter dem Mikroskope kaum krystallinisch, fast flockig aussah. Es war zinnhaltig und wurde daher in schwacher Chlorwasserstoffisäure gelöst, und die braune Lösung durch Schwtfelwasserstoif" "ntzinnt. Das Filtrat, zur Krystallisation ver- 
d:ımpft, erfüllte sich allmählich mit kleineı, glänzenden Blättern, die gepresst und getrocknet gegen $280^{\prime \prime}$ schmolzen,

1. $0,1876 \mathrm{Grm}$. gaben $0,3598 \mathrm{Grm}$. $\mathrm{CO}_{2}$ und $0,0976 \mathrm{Grm} . \mathrm{H}_{2} \mathrm{O}$.

2. $0,1645 \mathrm{Grm}$. gaben bei $15,6^{\circ}$ und $745,3 \mathrm{Mm}$. 16,6 Cem. N.

3. 0,1597 Grm. gaben 0,1928 Grm. AgCl.

\begin{tabular}{ccccc} 
& \multicolumn{3}{c}{ Gefunden: } & \multicolumn{2}{c}{ Berechnet für } \\
& 1. & 2. & 3. & $\mathrm{C}_{10} \mathrm{H}_{6}\left(\mathrm{NH}_{2}\right)_{2}, 2 \mathrm{HCl}:$ \\
$\mathrm{C}$ & 52,29 & - & - & $51,95^{\circ} .0$ \\
$\mathrm{H}$ & 5,75 & - & - & $5,19 .$, \\
$\mathrm{N}$ & - & 11,76 & - & $12,12 . "$ \\
$\mathrm{Cl}$ & - & - & 29,87 & $30,73 .$,
\end{tabular}

Bei der Reduction war also Kohlendioxyd abgespalten, und das Chlorhydrat eines Diamidonaphtalins gebildet worden. Um nun die Base abzuscheiden, wurde die Lösung mit Ammoniak versetzt, wodurch ein aus kleinen Nadeln bestehender Niederschlag entstand. Zur Reinigung wurde er in kaltem Alkohol gelöst, und das Filtrat mit Wasser versetzt, wodurch nach kurzer Zeit die Lösung zu einer Masse kleiner Nadeln erstarrte. Der Schmelzpunkt clieser Verbindung lag bei $64^{\prime \prime}-65^{\prime \prime}$; nach wiederholtem Umkrystallisiren aus schwachem Weingeist wurde sie in langen, farblosen Nadeln vom Schmelzp. $65^{0}$ erhalten. Es war also das zuerst von Aguiar ${ }^{1}$ ) aus $\beta$-Dinitronaphtalin dargestellte Diamidonaphtalin, dessen Schmelzpunkt nach diesem Forscher bei 66,5 " liegen soll. Die Identität wurde auch dadurch bestätigt, dass die Wasserlösung der Base mit Eisenchlorid erst eine dunkelbraune Färbung und nachher einen kastanienbraunen Niederschlag gab. Aus Gründen, die oben (S. 163) hervorgehoben worden sind, muss man das $\beta$-Dinitronaphtalin als ein Periderivat ansehen und also auch der hier in Rede stehenden Dinitro-c-naphtoësäure die Constitution

beilegen.

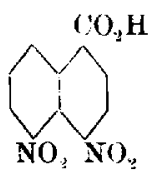

1) Ber. 7, 3019 . 
264 Fkstrand: Zur Kenntniss der Naphtoësäuren.

Ein anderer Reductionsversuch wurde so ausgeführt, dass die Dinitrosäure in Fisessig gelöst und zur heissen Lösung etwas rauchende Chlorwasserstoffsäure und dann Zinnfeile gesetzt wurde, wobei eine heftige Reaction eintrat, und die Lösung eine braune Farbe anuahm. Nach einigem Kochen wurde Wasser zugesetzt, and Schwefelwasserstoff eingeleitet; das zur Trockne eingedampfte Filtrat, vom Schwefelzinn nach dem Behandeln mit warmem Wasser von Neuem filtrirt, gab mit Chlorwasserstoffsäure bei genügender Concentration einen aus feinen, grünlichgelben Nadeln bestehenden Niederschlag, dessen Schmelzpunkt über $300^{\circ}$ lag. Das zwischen Löschpapier getrocknete Salz entwickelte bei gelinder Wärme Chlorwasserstoff.

0,1600 Grm., getrocknet bei $110^{\circ} \mathrm{zu}$ constantem Gewicht, gaben bei $16^{\circ}$ und $758,4 \mathrm{Mm}$. $16,2 \mathrm{Cem}$. N.

$$
\begin{aligned}
& \text { Gefunden: Ber.f. } \mathrm{CO}_{2} \mathrm{H} . \mathrm{C}_{10} \mathrm{H}_{5}\left(\mathrm{NH}_{2} \mathrm{l}_{2} \mathrm{HCl}: \quad \mathrm{C}_{10} \mathrm{H}_{6}\left(\mathrm{NH}_{2}\right)_{2} 2 \mathrm{HCl}\right. \\
& \text { N } 11,9: 9 \\
& \text { 11. } 74 \\
& 12,12 \% \text {. }
\end{aligned}
$$

Durch diese Analyse lässt sich also kaum entscheiden, ob hier das Chlorhydrat der Diamidonaphtoësäure oder dasjenige des Diamidonaphtalins vorlag, obwohl das Verhalten der Verbindung mehr für die letzte Annalyse sprach; denn A mmoniak rief in ihrer wässrigen Lösung einen Niederschlag hervor, der klebrig und harzähnlich war, aber dennoch nach einiger Zeit von grünen Krystallnadeln durchzogen war. Dieses Harz war sehr schwer löslich in Wasser und Ammoniak, leicht löslich dagegen in Alkohol, nach dessen Verdunsten wieder ein von Nadeln durchsetztes Harz zurïckblieb. Um diese Verhältnisse womöglich aufzuklären, unterwarf ich eine grössere Quantität der Dinitrosäure demselben Verfahren, erhielt aber dann eine Krystallmasse von verschiedenem Aussehen; es waren nämlich kleine Tafeln und nicht wie vorher Nadeln. Die Zusammetzung war auch eine andere $(\mathrm{C}-61,04, \mathrm{H}-5,65, \mathrm{~N}-10,89, \mathrm{Cl}-15,24)$, auf ein Gemenge mehrerer Verbindungen hindeutend. Beim Versetzen mit Ammoniak gab die chlorwasserstoffsaure Lösung jetzt einen nur theilweise in Alkohol löslichen Niederschlag; aus der alkoholischen Lösung setzte sich beim Verdunsten (ine griine, harzähnliche Masse ab, die in Chlorwasserstuff- 
säure leicht löslich war, und dessen Chlorhydrat in feinen, schwarzgränen Nadeln krystallisirte.

0,1164 Grm. dieser Nadeln gahen bei $12,4^{9}$ and $756,8 \mathrm{Mm}$. $11,5 \mathrm{Ccm}$. N.

$$
\text { N Gefunden: } \quad \text { Ber, f. } \underset{11,79}{\mathrm{C}_{10} \mathrm{H}_{8}\left(\mathrm{NH}_{2}\right)_{2}} 2 \mathrm{HCl} \text { : }
$$

Nach ihrer Analyse und ihrem sonstigen Verhalten muss die Verbindung mit der oben angeführten, bei dem ersten V ersuche als einzig löslichem Produkte erbaltenen identisch gewesen sein. Die chlorwasserstoffsaure Mutterlauge von den schwarzgrünen Nadeln gab beim Verdunsten einen Theer, der nicht woiter untersucht werden konnte. Was aber den in Alkohol unlöslichen Theil des Ammonniederschlages betrifft, so wurde er mehrmals mit Alkohol ausgekocht und bildete dann ein russschwarzes Pulver, unlöslich in Chlorwasserstoffsäure, schwer löslich in Ammoniak, aber mehr löslich in Natronlauge. Aus der bramvioletten Natronlösung wurde mit Chlorwasserstoffsäure ein sehr voluminöser Niederschlag erhalten, der, getrocknet und pulverisirt, lange mit schwacher Chlorwasserstoffsäure gewaschen wurde. Der Rückstand war ein schwarzes, unschmelzbares Pulver.

1. 0,1644 Grm. dieses Pulvers gaben 0,3954 Grm. CO, und 0,0607 (र) $\mathrm{XI}_{2} \mathrm{O}$.

2. 0,1634 Grm. gaben bei $14,6^{\circ}$ und $751,2 \mathrm{Mm} .17,5 \mathrm{Ccm}$. N.

$$
\begin{aligned}
& \text { Gefunden: Berechnet für }
\end{aligned}
$$

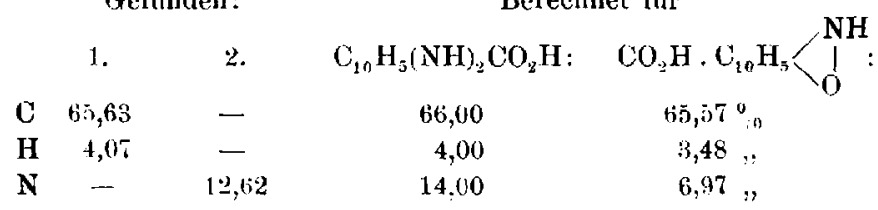

Das schwarze Pulver scheint also gemäss diesen Analysen wenigstens seiner Hauptmasse nach eine Diimido- $\alpha$ naphtoësäure $\mathrm{CO}_{2} \mathrm{HC}_{10} \mathrm{H}_{5}<\underset{\mathrm{NH}}{\mathrm{NH}}$ gewesen zu sein, wahrscheinlich etwas verunreinigt durch Oximidonaphtoësäure, deren Bildung dem wiederholten Auskochen mit Alkohol und verdünnter Chlorwasserstoff säure zuzuschreiben ist. 
266 Ekstrand: Zur Kenritniss der Naphtoësäuren.

Aus dem Obigen geht berror, dass die Reduction der Dinitronaphtoësäure weniger glatt verläuft, wenn die Säure vorher in Eisessig gelöst ist, als wem sie in fester Form mit Zinn und Chlorwasserstoffäure behandelt wird; im letzten Falle bildet sich hauptsïchlich das Chlorhydrat des Diamidonaphtalins, im ersten dagegen sowohl dieses Chlorhydrat wie auch mebrere reducirte Säuren, nämlich in erster Linie Diamido- und als deren Oxydationsprodukte Diimido- und vielleicht Oximidonaphtoësäure. Zuweilen fiel schon am Anfange des Reductionsprocesses ein schwarzes, unkrystallinisches Pulver aus ter Eisessiglösung, und die Ausbeute an löslichen Verbirdungen war dann ganz gering. Die unkrystallinische, unhandliche Beschaffenheit eines Theils der gebildeten Produkte lud nicht zur weiteren Untersuchung ein. Uebrigens habe ich auch versucht, die Reduction der Dinitrosäure in ammoniakalischer Lösung mit Ferrosulfat durchzuführen, aber obne besseren Erfolg. Nach vollendeter Reduction wurde die ammoniakalische Lösung mit Chlorwasserstoffsäure versetat, wobei ein geringer Niederschlag von blaugrünen Flocken entstand. Diese waren unschmel\%bar, wie die Diazinnaphtoësäure, und wahrscheinlich damit identisch. Die chlorwasserstoffsaure Mutterlauge davon gab beim Verdunsten auf dem Wasserbade eine Krystallmasse von kleinen Tateln, in deren Wasserlösung Ammoniak einen Niederschlag von kleinen Nadeln erzengte; aus schwachem Weingeist krystallisirte diese Verbindung in langen, farblosen Nadeln rom Schmelzp. 65"; es war somit das oben erwähnte Diamidonaphtalin $\left(1,1^{\prime}\right)$. In der mit Ferrosulfat reducirten ammoniakalischen Lösung muss also clie Diamido- $\alpha$-nlaphtoësäure vorhanden gewesen sein, obwohl schon durch das Frlitzen mit überschüssiger Chlorwasserstoffsüure auf dem Wasserbade Kohlendioxyd ausgetrieben worden ist. Die Darstellung der freien Diamidosäure scheint also mit verschiedenen Schwierigkeiten verbunden zu sein. Auch die Concentration einer ammoniakalischen Lösung behufs Ausfällung mit Essigsäure würde wahrscheinlich nicht ohne theilweise Oxydation vor sich gehen können. 
In der salpetersauren Mutterlauge von der Bereitung der Dinitro- $\alpha$-naphtoësäure vom Schmelzp. $265^{\prime \prime}$ waren noch verschiedene Verbindungen vorhanden; es ist mir gelungen, daraus zwei neue Dinitronaphtoësäuren abzuscheiden. $\mathrm{Zu}$ diesem Zwecke wurde die Mutterlauge mit viel Wasser versetzt, und der gewaschene Niederschlag mit Sodalösung digerirt. $E_{s}$ blieb dabei ein indifferenter Körper ungelöst, der aus Eisessig in langen, gelben Nadeln lirystallisirte, welche nach wiederholtem Umkrystallisiren bei 212" schmolzen und danach das sogenannte $\alpha$-Dinitronaphtalin waren. Die Lösung der Natriumsalze wurde zur Krystallisation verdunstet und erfüllte sich beim Erkalten mit kleinen, gelben Krystallschuppen; aus der Mutterlauge schied sich bei fortgesetztem Eindampfen noch etwas von derselben Verbindung aus. Versuchte ich aber das Eindampfen noch weiter zu treiben, so wurde die Lösung immer dunkler und gạb beim Versetzen mit Chlorwasserstoffsäure unter lebhafter Gasentwicklung ein Harz, woraus keine krystallinischen Stoffe zu erhalten waren. Die krystallisirten Natriumsalze wurden thunlichst von Mutterlauge befreit, in Wasser gelöst und mit Chlorwasserstoffsäure gefällt.

Es zeigte sich bald, dass der Niederschlag aus mehreren Säuren bestand; denn nachdem die alkoholische Lösung des Niederschlages mit Chlorwasserstoffgas gesättigt war, schieden sich daraus theils lange, feine Nadeln, theils harte, rhombische Krystalle. Beim Digeriren des Gemenges mit Ammoniak blieben ıun die Nadeln ungelöst zurück, während die harten Krystalle gelöst wurden. Es waren also hier zwei Säuren vorhanden, von denen die eine durch Alkohol uut Chlorwasserstoff in ihren Aethyläther übergefïhrt wurde, die andere dagegen unverändert blieb. Die erstere schmolz bei $215^{\circ}$, die letztere bei $218^{\circ}$.

Dinitro- $\alpha-11$ aphtoësäure vom Schmelzp. $218^{\circ}$.

Diese Säure, deren alkoholische Lösung von Chlorwasserstoff nicht verändert wurde, schied sich aus der ammoniakalischen Lösung durch Chlorwasserstoffsäure aus; der Niederschlag wurde in wenig warmem Alkobol gelöst, woraus 
die Säure in harten, rhombischen Krystallen von tiefgelber Farbe anschoss. Sie schmolz unter Aufblähen bei $218^{\circ}$.

1. 0,1379 Grm. gaben bei $17,8^{\circ}$ und $762,4 \mathrm{Mm}$. 12,6 Ccm. N.

2. 0,1766 Grm. gaben 0,3264 Grm. $\mathrm{CO}_{2}$ und 0,0484 Grm. $\mathrm{H}_{2} \mathrm{O}$.

Gefunden:

$\begin{array}{ccc} & 1 . & 2 . \\ \mathbf{C} & - & 50,39 \\ \mathbf{H} & - & 3,00 \\ \text { N } & 10, \mathrm{~s} 0 & -\end{array}$

Berechnet fïr $\mathrm{C}_{10} \mathrm{H}_{5}\left(\mathrm{OO}_{2}\right)_{2} \mathrm{CO}_{2} \mathrm{H}$ : $50,38{ }^{0} i_{0}$ 2,29 10,68,

Die Säure war sehr leicht löslich in Alkohol und löste sich auch in heissem Wasser, woraus sie in feinen Nadeln krystallisirte.

Der Aethyläther, dargestellt durch Erwärmen des Silbersalzes mit Jodäthyl auf dem Wasserbade, krystallisirte aus Alkohol in langen, harten, gelben Nadeln vom Schmelzp. $129^{\circ}$.

0.1888 Grm. gaben bei $15,4^{\circ}$ und 755 Mus. 15,9 Cem. N.

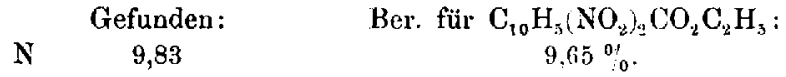

Das Calciumsalz $\left(\mathrm{C}_{10} \mathrm{H}_{5}\left(\mathrm{NO}_{3}\right)_{2} \mathrm{CO}_{2}\right)_{2} \mathrm{Ca}+7 \mathrm{H}_{2} \mathrm{O}$ wurde durch Kochen der Säure mit Wasser und Calciumcarbonat erhalten und krystallisirte in dünnen, breiten, glänzenden Nadeln von gelber Farbe, sehr leicht löslich in Wasser.

0,1064 Grm., getrocknet zwischen Löschpapier, verloren beim Erhitzen auf $141^{\circ} 0,0197$ Grm. $\mathrm{H}_{2} \mathrm{O}=18,51 \%$; ber. $18,31 \% \%_{0} \mathrm{H}_{2} \mathrm{O}$; der Rückstand, 0,0867 Grm., gab 0,0210 Grm. CaSO $4=7,11 \%$ Ca; ber. $7.11 \% \mathrm{Ca}$.

Die Ausbeute an der Säure war sehr gering. Durch Härte und Aussehen der Krystalle erinnert sie sehr an die Mononitro- $\alpha$-naphtoësäure vom Schmelzp. 215 die Unmöglichkeit, den Aethyläther durch Alkohol und Chlor. wasserstoff zu erhalten, ist für beide kennzeichnend. Es lag also die Vermuthung nahe, dass die hier in Rede stehende Dinitro-c-naphtoësäure die Carboxylgruppe und die zuletzt eingefuhrte Nitrogruppe in zwei benachbarten $a$-Stellungen enthalte. Wie schon früher bemerkt, entstehen bei der Reduction derartiger Derivate leicht Naphtostyrilverbindungen, das war auch hier der Fall. Die Säure wurde 
Ekstrand: Zur Kenntniss der Naphtoësäuren. 269 mit Zinn und Chlorwasserstoffsäure erhitzt; im Antange war die Einwirkung kaum merkbar, aber nach einigem Kochen wurde die Flüssigkeit mit langen, hellgelben Nadeln erfüllt, die zinnfrei und in kaltem Wasser ziemlich schwer löslich waren; der Schmelzpunkt lag zu hoch, um bestimmt werden zu können.

1. 0,0894 Grm gaben $0,1946 \mathrm{Grm} . \mathrm{CO}_{2}$ und $0,0428 \mathrm{Grm} . \mathrm{H}_{2} \mathrm{O}$

2. 0,0952 Grm. gaben bei $13,2^{\circ}$ und $768,2 \mathrm{Mm}$. $10 \mathrm{Ccm}$. N.

\begin{tabular}{cccc}
\multicolumn{3}{c}{ Gefunden: } & Berechnet für \\
\multicolumn{1}{c}{1.} & 2. & $\mathrm{C}_{10} \mathrm{H}_{6} \mathrm{NH}_{2} \mathrm{NHCO} . \mathrm{HCl}:$ \\
$\mathrm{C}$ & 59,40 & - & $59,86 \%$ \\
$\mathrm{H}$ & 5,25 & - & $4,08 \%$ \\
$\mathrm{~N}$ & - & 12,72 & $12,69 \%$.
\end{tabular}

Obwohl das Material ziemlich gering war, scheint doch die angeführte Formel durch die Analyse hinreichend bestätigt, und es lag also das Chlorhydrat eines Amidonaphtostyrils vor. Dem hier erhaltenen Amidonaphtostyril kann wegen seiner Entstehungsweise nur die Formel:

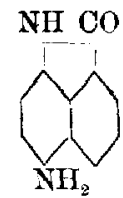

zukommen, und daher muss auch die Dinitro- $\alpha$-naphtoësäure vom Schmelzp. $218^{\circ}$ nach der Formel:

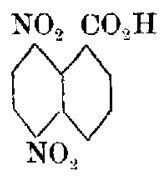

rusammengesetzt sein.

Wenn die ammoniakalische Lösung der Säure mit Schwefelwasserstoff gesättigt wurde, zeigte sich zwar keine Farbenveränderung, aber es fiel etwas Schwefel aus und daneben auch in geringer Menge ein rother, krystallinischer Körper, der in Alkohol ziemlich schwer löslich war und daraus in kleinen, in Ammoniak unlöslichen Nadeln krystallisirte; er war nach seinem Verhalten wahrscheinlich ein Nitronaphtostyril. Das früher (S. 180) beschriebene, durch 
Nitrirung des Naphtostyrils dargestellte Nitronaphtostyril muss nach der dortigen Auseinandersetzung dieselbe Constitution wie dàs aus der Dinitrosäure direct erhaltene haben.

Dinitro-ধ-naphtoësäure vom Schmelzp. 215".

Der Aethyläther dieser Säure krystallisirte schon beim Erkalten der mit Chlorwasserstoff gesättigten alkoholischen Lösung grösstentheils aus und wurde nach dem Digeriren mit Ammoniak ans Alkohol umkrystallisirt. Der so gereinigte Aether wurde mit concentrirter Schwefelsäure auf dem Wasserbade erhitzt, bis sich alles gelöst hatte, und beim Erkalten erstarrte die Masse dann krystallinisch durch ausgeschiedene Dinitrosäure; nach Zusatz von Wasser wurde der Niederschlag mit Ammoniak digerirt, die gelöste Säure wieder ausgefällt und in Alkohol gelöst, woraus sie in kleinen, farblosen, seideglänzenden, breiten Nadeln oder Blättern vom Schmelzp. $215^{\circ}$ krystallisirte.

1. 0,1657 Grm. gabes bei $16^{\circ}$ und $776,8 \mathrm{Mm}, 15$ Cen. N.

2. 0,1510 Grm, gaben 0,2804 Grm. $\mathrm{CO}_{2}$ und 0,0394 Girm. $\mathrm{H}_{2} \mathrm{O}$. Gefunden:

Berechnet frir

$\begin{array}{cccc} & 1 . & 2 . & \mathrm{C}_{10} \mathrm{H}_{3}\left(\mathrm{NO}_{2}\right)_{2} \mathrm{CO}_{2} \mathrm{H}: \\ \mathrm{C} & - & 50,66 & 50,380^{\circ} \\ \mathbf{H} & - & 2,85 & 2,29 " \\ \mathrm{~N} & 10,93 & - & 10,68 "\end{array}$

Die Säure war leicht löslich in Alkohol und Eisessig und auch in warmem Aether, schwer löslich dagegen in Benzol und Ligroïn; in kochendem Wasser war sie etwas löslich und krystallisirte daraus in kleinen, farblosen Schuppen.

Der Aethyläther, erhalten auf die oben angegebene Weise durch Sättigen der alkoholischen Lösung der Säure mit Chlorwasserstoff, krystallisirte in feinen, verfilzten Nadeln vom Schmelzp. 137\%. Dieser Aether ist schwerer löslich in Alkohol als die Säure selbst.

Das Calciumsalz, erhalten durch Kochen der Säure mit Wasser und Calciumcarbonat, krystallisirte in kleinen, zusammengeballten Nadeln, die, weil etwas klebrig, nicht wohl zwischen Löschpapier getrocknet werden konnten.

0,1513 Grm., bei $150^{\circ}$ getrocknet, gaben 0,0359 Grm. $\mathrm{CaSO}_{4}=$ $6,98 \% \mathrm{Ca}$; ber. f. $\left(\mathrm{C}_{10} \mathrm{H}_{5}\left(\mathrm{NO}_{2}\right)_{2} \mathrm{CO}_{2}\right)_{2} \mathrm{Ca}: 7,11 \% \mathrm{Ca}$. 


\section{Nitroamido- $\ell-$ naphtoësäure.}

Die ammoniakalische Lösung der vorstehenden Dinitro$u$-naphtoësäure wurde mit Schwefelwasserstoff gesättigt, wobei Rothfärbung eintrat. Nachdem der überschüssige Schwefelwasserstoff durch Erhitzen auf dem Wasserbade entfernt worden war, wurde die Lösung filtrirt und mit Essigsäure versetzt. Der jetzt entstandene flockige Niederschlag, der ïbrigens sehr gering war, wurde abfiltrirt und zum rothgelben Filtrate etwas Natronlauge gesetzt, um die saure Reaction abzustumpfen; es fiel dann ein aus kleinen Nadeln bestehender Niederschlag aus, der in feuchtem Zustande rothgelb, in getrocknetem gelb war. Der Schmelzpunkt lag gegen $110^{\circ}$, die Verbindung fing aber schon an, theilweise zu schmelzen.

0,1765 Grm. gaben bei $17,3^{\circ}$ and $758 \mathrm{Mm} .18 \mathrm{Ccm}$. N.

$$
\begin{aligned}
& \text { Gefunden: Ber. für } \mathrm{C}_{10} \mathrm{H}_{5} \mathrm{NH}_{2} \mathrm{NO}_{2} \mathrm{CO}_{2} \mathrm{H} \text { : } \\
& \mathrm{H} 12,01212,06 \% \text {. }
\end{aligned}
$$

Beim Erhitzen der Dinitro- $\alpha$-naphtoësäure mit Zinn und Chlorwasserstoffsäure krystallisirte schon während des Kochens ein aus kleinen, farblosen Nadeln bestehendes Pulver aus, wahrscheinlich das Zinndoppelsalz rom Chlorhydrate der Diamidonaphtoësäure. Es war leicht löslich in Wasser, und das Zinn wurde mit Schwefelwasserstoff entfernt. Nach dem Eindampfen des Filtrates wurden grosse, tarblose Krystallb]ätter erhalten; aber beim Uebergiessen derselben mit warmem Wasser wurde die Lösung sogleich braunroth, und beim Verdampfen wurden nun ganz kleine Krystalle erhalten, was auf irgend eine Veränderung, vielleicht Oxydation der Verbindung, hindeutet. Um dem vorzubeugen, wurde die Lösung mit Zinn und Chlorwasserstoffsäure erhitzt, wobei die Farbe etwas heller wurde. Nachdem das Zinn entfernt und die Lösung stark concentrirt worden war, wurde sie von feinen Nadeln exfüllt, die unter Aufblähen bei $250^{\circ}$ schmolzen und das Dichlorhydrat der Diamido$\alpha$-n iphtoësäure darstellten.

1,1280 Grm, gaben bei $13^{\circ}$ und $760 \mathrm{Mm} .11 \mathrm{Ccm} . \lambda$.

$$
\begin{aligned}
& \text { Gefunden: Ber. für } \mathrm{CO}_{2} \mathrm{H} . \mathrm{C}_{10} \mathrm{H}_{0}\left(\mathrm{NH}_{2}\right)_{2} 2 \mathrm{HCl} \text { : } \\
& \text { N } 10,32 \quad 10,18 \% \text {. }
\end{aligned}
$$




\section{Ekstrand: Zur Kenntniss der Naphtoësäuren.}

Ammoniak rief in der Lösung des obigen Chlorhydrates keinerlei Farbenveränderung oder Niederschlag hervor. Die ammoniakalische Lösung wurde nun mit Essigsäure angesäuert und zur Trockniss verdampft; der Rückstand wurde mit warmem Alkohol ausgezogen, und daraus schieden sich kleine, braune, nadelförmige Krystalle aus, die unschmelzbar zu sein schienen und, weil leicht löslich in Ammoniak, wahrscheinlich die freie Diamidosäure waren.

Was die Constitution der Dinitro- $t$-naphtoësäure vom Schmelzp. $215^{\prime \prime}$ betrifft, so kann nur soviel gesagt werden, dass die zuletzt hinzugetretene Nitrogruppe eine $\beta$-Stellung einnehmen muss, weil von der Mononitro- $\alpha$-naphtoësäure $\left(1,4^{\prime}\right)$ nur zwei Dinitrosäuren mit lauter $\alpha$-Stellungen ableitbar sind, nämlich $\left(1,1^{\prime} 4^{\prime}\right)$ und $\left(1,4,4^{\prime}\right)$, welche beide oben beschrieben sind; dagegen reichte das Material nicht hin, um zu entscheiden, ob die beiden Nitrogruppen in demselben oder in verschiedenen Benzolkernen vorkommen.

Trinitro- $\alpha$-naphtoësäure vom Schmelzp. $283^{\circ}$.

Um aus der Peri-nitro- $\alpha$-naphtoësäure vom Schmelzp. $215^{\circ}$ höher nitrirte Naphtoësäuren zu bekommen, wurde die genannte Nitronaphtoësäure portionenweise in eine abgekühlte Mischung von concentrirter Schwefelsäure und rauchender Salpetersäure unter Umschütteln eingetragen. Es löste sich hierbei Alles ohne Erwärmen auf, und nach einigen Stunden hatten sich grosse Krystalle abgesetzt, die von der Mutterlauge getrennt wurden. Diese waren, wie gleich gezeigt werden soll, ein Trinitronaphtalin, wogegen in der Mutterlauge von diesen Krystallen eine höhere Nitrosäure enthalten war. Zur Abscheidung derselben wurde die Mutterlauge mit viel Wasser versetzt, der entstandene Niederschlag gewaschen und wachher mit Ammoniak digerirt, worin sich ein Theil mit braunrother Farbe löste. Die ammoniakalische Lösung wurde mit Chlorwasserstoftsäure gefällt, wobei ein harziger Niederschlag ausfiel, der in warmem Alkohol leicht löslich war; aus der gesättigten Lösung krystallisirten bald beim Erkalten grosse, breite, meistens keilförmig zngespitzte 
Ekstrand: Zur Kenntniss der Naphtoësüuren.

Nadeln von brauner Farbe, die nach mehrmaligem Umkrystallisiren aus Alkohol bei $283^{\circ}$ schmolzen.

1. 0,1493 Grm. gaben bei $13^{\circ}$ und $764,2 \mathrm{Mm}$. 17,2 Cem. $\mathrm{N}$.

2. 0,1137 Grm. gaben $0,1788 \mathrm{Grm} . \mathrm{CO}_{2}$ and $0,0237 \mathrm{Grm}, \mathrm{H}_{2} \mathrm{O}$. Gefunden:

Berechnet für

$\begin{array}{cccc} & 1 . & 2 . & \mathrm{C}_{10} \mathrm{H}_{4}\left(\mathrm{NO}_{2}\right)_{3} \mathrm{CO}_{2} \mathrm{H}: \\ \mathrm{C} & - & 42,92 & 42,99 \% \\ \mathrm{H} & - & 2,28 & 1,63 \% \\ \mathbf{N} & 13,88 & - & 13,68 \% .\end{array}$

Diese Trinitronaphtoësäure hatte einen intensiv bitteren Geschmack, so dass schon die leiseste Spur davon einen lange andauernden Ekel hervorrief, was insofern eigenthümlich ist, als unter den von mir untersuchten Derivaten der $\alpha$ Naphtoësäure nur die Dichlornitronaphtoësäure ein derartiges Verhalten zeigt; vielleicht deutet dies auf eine ähnliche Constitution der beiden Derivate hin.

Der Aethyläther, aus dem Silbersalze durch Erhitzen mit Jodäthyl erhalten, krystallisirte aus Alkohol in kleinen, braunen Prismen vom Schmelzp. $131^{\circ}$.

$0,1783 \mathrm{Grm}$. gaben bei $19,4^{\circ}$ und $766 \mathrm{Mm}, 19,4 \mathrm{Ccm}$. N.

N Gefunden: $\quad$ Ber. für $\mathrm{C}_{10} \mathrm{H}_{4}\left(\mathrm{NO}_{2}\right)_{3} \mathrm{CO}_{2} \mathrm{C}_{2} \mathrm{H}_{5}$ :

Das Calciumsalz, $\left(\mathrm{C}_{10} \mathrm{H}_{4}\left(\mathrm{NO}_{2}\right)_{3} \mathrm{CO}_{2}\right)_{2} \mathrm{Ca}+5 \mathrm{H}_{2} \mathrm{O}$, durch Kochen der Säure mit Wasser und Calciumcarbonat erhalten, war leicht löslich in warmem Wasser und krystallisirte beim Erkalten in braunen Blättern oder Nadeln, die beim Trocknen fast farblos wurden.

0,2843 Grm., zwischen Löschpapier getrocknet, verloren beim Erbitzen auf $150^{\circ}-160^{\circ} 0,0341$ Grm. $\mathrm{H}_{2} \mathrm{O}=11,99 \%$; ber. $12,12 \% \mathrm{H}_{2} \mathrm{O}$; der Rückstand, 0,2502 Grm., gab 0,0489 Grm. $\mathrm{CaSO}_{4}=5,75 \% \mathrm{Ca}$; ber. $6,13 \% \mathrm{Ca}$.

Trinitronaphtalin. Die oben genannten bei der Nitrirung der Nitronaphtoësäure erhaltenen grossen Krystalle waren unlöslich in Ammoniak und wurden aus kochendem Eisessig umkrystallisirt, wobei die Verbindung in gelblichen Prismen vom Schmelzp. $212^{\circ}-213^{\circ}$ anschoss. Sie war sehr schwer löslich, auch in heissem Alkohol.

$0,2580 \mathrm{Grm}$. gaben bei $14,2^{\circ}$ und $771,7 \mathrm{Mm} .34,2 \mathrm{Cem} . \mathrm{N}$.
N
Gefunden:
16,15
Journal f. prakt. Chemle [2] Bd. 88 .
Ber. für $\mathrm{C}_{10} \mathrm{H}_{5}\left(\mathrm{NO}_{2}\right)_{3}$ :
$15,96 \%$. 
274 Ekstrand: Zur Kenntniss der Naphtoësäuren.

Gemäss dieser Analyse und wegen seiner völligen Indifferenz gegen Alkalien war der Körper also ein Trinitronaphtalin und zwar das sogenannte $\beta$-Trinitronaphtalin, dessen Schmelzpunkt nach Beilstein und Kuhlberg $\left.{ }^{1}\right)$ bei $213^{\circ}$, nach Aguiar ${ }^{2}$ ) bei $218^{0}$ liegt. Die Angabe der Ersteren scheint durch meinen Versuch somit bestätigt zu werden.

Die Ausbeute an Trinitronaphtoësäure war bei der genannten Darstellungsweise, sowie bei etwas abgeänderten Versuchen sehr gering, wogegen das Hauptprodukt immer aus Trinitronaphtalin bestand, was natürlich von der gegenseitigen Stellung der Nitro- und Carboxylgruppe in der Mononitronaphtö̈säure abbängt; denn, wie ich früher (S. 162) gezeigt habe, geht dieselbe Nitro- $\alpha$-naphtoësäure schon beim Erhitzen mit Salpetersäure vom spec. Gew. 1,3 in das sogenannte $\beta$-Dinitronaphtalin über, weshalb es schwer fällt, aus der betreffenden Mononitro- $\alpha$-naphtoësäure höhere Nitroderivate darzustellen. Es ist mir z. B. noch nicht gelungen, eine Dinitro- $\alpha$-naphtoësäure daraus zu bekommen.

Trinitro- $\alpha$-naphtoësäure vom Schmelzp. $236^{\circ}$.

Dinitro- $\alpha$-naphtoësäure vom Schmelzp. $265^{\circ}$ wurde auf dem Wasserbade mit einem Gemisch von rother rauchender Salpetersäure und concentrirter Schwefelsäure erhitzt, bis sich alles gelöst hatte; am folgenden Tage wurde viel Wasser zugesetzt, wobei ein Niederschlag entstand, der, von der Mutterlauge getrennt, mit wenig Alkohol gekocht wurde. Es zeigte sich dann, dass ein Theil des Produktes in Alkohol leicht löslich, ein anderer darin schwer löslich war. Der leicht lösliche Theil enthielt eine Säure, die nach vergeblichen Versuchen, sie durch Umkrystallisiren aus schwachem Weingeist $\mathrm{zu}$ reinigen, in starkem Alkohol gelöst wurde und daraus bei langsamer Krystallisation in harten, blassgelben Nadeln vom Schmelzp. $236^{\circ}$ anschoss.

0,1283 Grm, gaben bei $12,2^{\circ}$ und $774,2 \mathrm{Mm}$. 14,6 Cem. $\mathrm{N}$.
Gefunden:
N 13,93
Ber. für $\mathrm{C}_{10} \mathrm{H}_{4}\left(\mathrm{NO}_{2}\right)_{3} \mathrm{CO}_{2} \mathrm{H}$ :
$13,68 \%$.

1) Ann. Chem. 169, 96.

2) Ber. 5,375 . 
Der Aethyläther, dargestellt aus dem Silbersalze der Säure und Jodäthyl, krystallisirte aus Alkohol in kleinen, büschelförmig vereinigten Nadeln vom Schmelzp. 191. . Der Aether war schwerer löslich in Alkohol, als die Säure selbst.

0.1381 Grm. gaben $0,2380 \mathrm{Grm} . \mathrm{CO}_{2}$ und $0,0449 \mathrm{H}_{2} \mathrm{O}$.

$\begin{array}{ccc} & \text { Gefunden: } & \text { Ber. für } \mathrm{C}_{10} \mathrm{H}_{4}\left(\mathrm{NO}_{2}\right)_{8} \mathrm{CO}_{2} \mathrm{C}_{2} \mathrm{H}_{5} \text { : } \\ \mathrm{C} & 46,99 & 46,57 \% \\ \mathrm{H} & 3,54 & 2,65 \%\end{array}$

Trinitro- $\alpha$-naphtoësäure vom Schmelzp. $293^{\circ}$.

Neben der vorigen in Alkohol leicht löslichen Trinitronaphtoësäure bildete sich auch, je nach den Umständen, mehr oder weniger von einer in Alkohol schwer löslichen Säure, die nach Umkrystallisiren aus Alkohol in kleinen, harten, blassgelben, kubischen Krystallen erhalten wurde. Der Schmelzpunkt lag bei $293^{\circ}$, obwohl die Krystalle schon früher zu erweichen anfingen.

$0,1766 \mathrm{Grm}$. gaben bei $14,4^{\circ}$ und $758,5 \mathrm{Mm} .20,4 \mathrm{Ccm} . \mathrm{N}$.

$\mathbf{N} \quad \begin{gathered}\text { Gefunden: } \\ \mathbf{1 3}, 78\end{gathered} \quad$ Ber. für $\mathrm{C}_{10} \mathrm{H}_{4}\left(\mathrm{NO}_{2}\right)_{3} \mathrm{CO}_{2} \mathrm{H}:$

Der Aethyläther, erhalten durch Sättigen der alkoboliscben Lösung der Säure mit Chlorwasserstoff, krystallisirte aus Alkohol in farblosen Nadeln vom Schmelzp. 150".

$0,2379 \mathrm{Grm}$. gaben 0,4047 Grm. $\mathrm{CO}_{2}$ und 0,0699 Grm. $\mathrm{H}_{2} \mathrm{O}$.

$\begin{array}{ccc} & \text { Gefunden: } & \text { Ber. f. } \mathrm{C}_{10} \mathrm{H}_{4}\left(\mathrm{NO}_{3}\right)_{3} \mathrm{CO}_{2} \mathrm{C}_{2} \mathrm{H}_{5}: \\ \mathrm{C} & 46,40 & 46,57 \% \\ \mathrm{H} & 3,23 & 2,65 \%\end{array}$

Nitroderivate des $\alpha$-Naphtamides.

$\mathrm{Zu}$ den bisherigen Versuchen, die $\boldsymbol{c}$-Naphtoësäure zu nitriren, sind drei Methoden angewandt worden, nämlich: Behandeln trockner Naphtoësäure mit Salpetersäure vom spec. Gew. 1,42, Einwirkung von rother, rauchender Salpetersäure auf eine eisessigsaure Lösung der Naphtoësäure oder schliesslich, wie es $\operatorname{Graeff}^{1}$ ) ausgeführt hat, Lösung des $\alpha$ -

1) Ber. 16, 2252 . 
Naphtonitrils in rauchender Salpetersäure und nachberige Verseifung des Nitroproduktes. Durch diese Methoden sind nun eigentlich blos zwei isomere Nitro- $a$-naphtoësäuren erhalten worden, welche im Vorigen beschrieben sind; ausserdem scheint aber Graeff aus einem Mononitronaphtonitril vom Schmelzp. $152^{\circ}-153^{\circ}$ noch eine andere isomere Nitro$c$-naphtoësäure rom Schmelzp. $255^{\circ}$ erhalten zu haben, wenn auch in so geringer Menge, dass sie kaum untersucht werden konnte. Diese Säure haibe ich bei meinen Versuchen nie in fassbarer Quantität erbalten können. Um womöglich zu dieser oder anderen Isomeren zu gelangen, habe ich schliesslich das $\alpha$-Naphtamid nitrirt und zu diesem Zwecke das Amid in überschüssiger Salpetersäure vom spec. Gew. 1,42 gelöst. Nach erfolgter Lösung wurde mit etwas rother Salpetersäure auf dem Wasserbade erhitzt; beim Erkalten schied sich eine gelbe Krystallmasse aus, die nach dem Auspressen mit Ammoniak digerirt wurde, um etwa gebildete Säure zu entfernen. Die von den Krystallen abgesogene Mutterlauge gab beim Versetzen mit Wasser einen flockigen, etwas klebrigen Niederschlag, der gleichfalls mit Ammoniak digerirt wurde. Die ammoniakalische Lösung lieferte mit Chlorwasserstoffsäure einen Niederschlag, der aus alkoholischer Lösung in feinen Nadeln krystallisirte, deren Schmelzpunkt nach mehrmaligem Umkrystallisiren bei $239^{\circ}$ lag. Es war also die schon bekannte Säure von der Constitution: $\left(1,4^{\prime}\right)$; durch eine Stickstoffbestimmung wurde noch bestätigt, dass eine Mononitronaphtoësäure vorlag.

Der in Ammoniak unlösliche Theil des Nitroproduktes wurde zuerst mit wenig Alkohol erwärmt, wobei hauptsächlich unverändertes Naphtamid aufgenommen wurde; das ungelöst Gebliebene wurde durch wiederholtes Auskochen mit Alkohol gereinigt und in heissem Eisessig gelöst, aus welchem beim Erkalten farblose Nadeln anschossen. Der Schmelzpunkt dieser lag bei $280^{\circ}$.

0,2347 Grm. gaben bei $19,3^{0}$ und $761,4 \mathrm{Mm}$. 26,3 Ccm. N.

$\mathrm{N} \quad \begin{array}{cc}\text { Gefunden: } & \text { Ber. für } \mathrm{C}_{10} \mathrm{H}_{8} \mathrm{NO}_{2} \mathrm{CONH}_{2}: \\ 13,17 & 12,96 \%\end{array}$


Es war also ein Nitronaphtamid gebildet worden. Auch in kochendem Alkohol war es sehr schwer löslich und krystallisirte daraus in feinen Nadeln; in Eisessig war es leichter löslich, besonders beim Erwärmen. Um die entsprechende Carbonsäure zu erhalten, wurde das Nitronaphtamid mit rauchender Chlorwasserstoffsäure im zugeschmolzenen Rohre 2 bis 3 Stunden auf $150^{\circ}-170^{\circ}$ erhitzt. Nach dem Erkalten war das Rohr mit gelben Nadeln erfüllt, die in Ammoniak unlöslich waren und nach Umkrystallisiren aus Eisessig bei $260^{\circ}-261^{\circ}$ schmolzen. Die Verbindung sublimirte leicht in gelben Nädelchen und war daher identisch mit dem früher (S. 174) erwähnten aus der Nitronaphtoësäure $\left(1,1^{\prime}\right)$ und Chlorwasserstoffsäure erhaltenen Dichlornaphtostyril.

Beim Nitriren des $\alpha$-Naphtamides in der angeführten Weise ist daher theils die Mononitro- $c$-naphtoësäure $\left(1,4^{\prime}\right)$, theils und, wie es scheint, in überwiegender Menge das Amid der Nitro- $\alpha$-naphtoësäure $\left(1,1^{\prime}\right)$ gebildet worden. Es muss natürlich angenommen werden, dass auch das der ersten Säure entsprechende Nitronaphtamid im ersten Stadium der Reaction entstanden ist; es ist daher bemerkensmerth, dass dieses Amid durch die fortgesetzte Einwirkung der Salpetersäure leichter, als das isomere Amid in die Carbonsäure übergeführt wird. Weder eine neue Nitrosäure, noch das Amid einer solchen habe ich bei meinen Versuchen erhalten können.

Beim Erhitzen des obigen Nitro- $\alpha$-naphtamids mit Zinn und Chlorwasserstoffsäure entstand ein dunkelgelber, krystallinischer Niederschlag, der zinnfrei und unlöslich in Wasser war. Er wurde daher in warmem Eisessig gelöst, und die daraus abgeschiedene Krystallmasse durch Kochen mit wenig Alkohol gereinigt. Die so erhaltene Verbindung bestand aus kleinen, grünen oder gelbgrünen Nadeln, die gegen $265^{\circ}$ schmolzen und leicht sublimirbar waren. Beim Erhitzen verbreitete die Verbindung einen eigenthümlichen unangenehmen Geruch.

1. 0,1808 Grm. gaben bei $17,4^{\circ}$ und $760,4 \mathrm{Mm} .10,7 \mathrm{Ccm}, \mathrm{N}$.

2. $0,2066 \mathrm{Grm}$. gaben $0,4842 \mathrm{Grm}$. $\mathrm{CO}_{2}$ und $0,0655 \mathrm{Grm} . \mathrm{H}_{2} \mathrm{O}$.

3. $0,1988 \mathrm{Grm}$. gaben $0,1325 \mathrm{Grm}$. AgCl. 
278 Ekstrand: Zur Kenntniss der Naphtoësäuren.

\begin{tabular}{ccccc} 
& \multicolumn{3}{c}{ Gefunden: } & Berechnet für \\
& 1. & 2. & 3. & $\mathrm{C}_{10} \mathrm{H}_{5} \mathrm{ClNHCO}:$ \\
$\mathrm{C}$ & - & 63,94 & - & $64,86 \%$ \\
$\mathrm{H}$ & - & 3,48 & - & $2,94 \%$ \\
$\mathrm{~N}$ & 6,99 & - & - & $6,88 \%$ \\
$\mathrm{Cl}$ & - & - & 16,49 & $17,44 "$
\end{tabular}

Nach den Analysen war die Substanz zwar nicht ganz rein, aber die berechnete Formel wird doch dadurch hinreichend begründet; es war somit ein Monochlornaphtostyril erhalten worden, dessen Bildungsweise durch folgendes Schema versinnlicht wird:

$$
\mathrm{C}_{10} \mathrm{H}_{6} \mathrm{NO}_{2} \mathrm{CONH}_{2}+\mathrm{HCl}+2 \mathrm{H}_{2}=\mathrm{C}_{10} \mathrm{H}_{5} \mathrm{ClNHCO}+\mathrm{NH}_{3}+2 \mathrm{H}_{2} \mathrm{O} \text {. }
$$

Diese Reaction ist, wie ersichtlich, derjenigen völlig analog, die bei der Reduction der entsprechenden Nitrosäure mit Zinn und Chlorwasserstoffsäure eintritt, nämlich:

$$
\mathrm{C}_{10} \mathrm{H}_{8} \mathrm{NO}_{2} \mathrm{CO}_{2} \mathrm{H}+\mathrm{HCl}+2 \mathrm{H}_{2}=\mathrm{C}_{10} \mathrm{H}_{5} \mathrm{ClNHCO}+3 \mathrm{H}_{2} \mathrm{O} \text {, }
$$

wie früher gezeigt wurde.

$$
\text { Oxy-c-naphtoësäure vom Schmelzp. } 169^{\circ} \text {. }
$$

Die Peri-amido- $c$-naphtoësäure $\left(1,1^{\prime}\right)$ wurde mit $1 \mathrm{Mol}$. Salpetersäure und Wasser zu einem Brei angerührt, in welchen Stickstofftrioxyd unter Kühlung eingeleitet wurde. Die Masse ging dabei theilweise in Lösung, uud bei Zusatz von mehr Wasser und gelindem Erwärmen löste sich fast Alles; die, wenn nöthig, filtrirte Lösung wurde auf dem Wasserbade erhitzt, wobei unter Stickstoffentwicklung kleine Nadeln ausfielen. Dasselbe Resultat wurde noch leichter in folgender Weise erhalten: die Amidosäure wurde in schwacher Alkalilauge gelöst, etwas mehr als 1 Mol. Kaliumnitrit zugesetzt, und die mit Eis gekühlte Lösung in gleichfalls gekühlte überschüssige verdünnte Schwefelsäure eingegossen. Es wurde so eine klare, rothbraune Lösung erhalten, die beim Erhitzen auf dem Wasserbade kleine Nadeln absetzte. Diese Nadeln waren das innere Anhydrid oder das Lacton der Oxysäure; um die Säure selbst daraus zu bekommen, wurde es mit schwacher Alkalilauge gekocht, und die erzielte Lösung der Oxysäure mit Chlorwasserstoffsäure gefällt. Der Niederschlag, aus feinen, glänzenden Nädelchen bestehend, 
wurde in Aether gelöst, und beim Verdunsten des Aethers setzten sich warzenförmige Aggregate von kleinen Nadeln $a b$, die etwas grünlichgelb gefärbt waren und bei $169^{\circ}$ schmolzen. Die gelbgrüne Farbe trat nach dem Trocknen noch schärfer hervor.

0,1797 Grm. gaben 0,4622 Grm. $\mathrm{CO}_{2}$ und 0,0752 Grm, $\mathrm{H}_{2} \mathrm{O}$.

$\begin{array}{ccc} & \text { Gefunden: } & \text { Ber. für } \mathrm{C}_{10} \mathrm{H}_{8} \mathrm{OHCO} \mathrm{HCO}_{2} \mathrm{H}: \\ \mathrm{C} & 70,17 & 70,21 \% \\ \mathrm{H} & 4,61 & 4,25 \%\end{array}$

Die Säure war leicht löslich in Alkohol und Aether, sowie in warmem Wasser. Die Leichtigkeit, mit der das Diazoderivat der Säure in das Lacton übergeht, liess zwar erwarten, dass beim Erhitzen der Säure selbst oder ihrer alkoholischen Lösung das Anhydrid entstehen würde; dies war jedoch nicht der Fall war, insofern die geschmolzene und wieder erstarrte Säure gegen $130^{\circ} \mathrm{schmolz}$; der Schmelzpunkt des Anhydrids liegt dagegen bei $108^{\circ}$.

Das Calciumsalz $\left(\mathrm{C}_{10} \mathrm{H}_{6} \mathrm{OH} . \mathrm{CO}_{2}\right)_{2} \mathrm{Ca}+3{ }^{1 /}{ }_{2} \mathrm{H}_{2} \mathrm{O}$ wurde leicht erhalten beim Kochen der Säure mit Wasser und Calciumcarbonat. Beim Verdampfen der Lösung schied sich eine Verbindung aus, die in warmem Wasser nicht mehr löslich war, während in der Mutterlauge ein leicht lösliches Salz zurückblieb, das in zu Tafeln vereinigten Nadeln krystallisirte und deren Zusammetzung der obigen Formel entsprach.

$0,2424 \mathrm{Grm}$., getrocknet zwischen Löschpapier, verloren bei $160^{\circ}$ $0,0324 \mathrm{Grm} . \mathrm{H}_{2} \mathrm{O}=13,36 \%$; ber. $13,20 \% \mathrm{H}_{2} \mathrm{O}$; der Rückstand, 0,2100 Grm., gab 0,0678 Grm. $\mathrm{CaSO}_{4}=9,47 \% \mathrm{Ca}$; ber. $9,66 \% \mathrm{Ca}$.

Die neutrale Lösung des Calciumsalzes gab mit Eisenchlorid einen violetten Niederschlag. Uebrigens scheint das Calciumsalz durch Kochen einer Zersetzung zu unterliegen, indem das Salz: $\mathrm{C}_{10} \mathrm{H}_{8} \mathrm{OCO}_{2} \mathrm{Ca}$ dabei gebildet wird.

\section{Naphtolacton.}

Das in der angegebenen Weise erhaltene Anhydrid der Oxysäure wurde bei gewöhnlicher Temperatur mit Ammoniak digerirt, rm etwa vorhandene Säure zu entfernen, und der 
280 Ekstrand: Zur Kenntniss der Naphtoësäuren.

Rückstand in schwachem Weingeist gelöst, woraus die Verbindung in langen, farblosen Nadeln vom Schmelzp. $108^{\circ}$ krystallisirte.

1. $0,1781 \mathrm{Grm}$. gaben $0,5070 \mathrm{Grm}$. $\mathrm{CO}_{2}$ und $0,0673 \mathrm{Grm} . \mathrm{H}_{2} \mathrm{O}$.

2. $0,1592 \mathrm{Grm}$. gaben $0,454^{3} \mathrm{Grm} . \mathrm{CO}_{2}$ und $0,0570 \mathrm{Grm}$. $\mathrm{H}_{2} \mathrm{O}$. Gefunden: 1.

2.

C $\quad 77,76$

77,82

H $\quad 4,21$

3,95

Das Lacton war bei gewöhnlicher Temperatur unlöslich in Alkalien. Aus einer heissen concentrirten Lösung in starkem Weingeist krystallisirte es beim Erkalten in zolllangen Nadeln, war auch leicht löslich in Schwefelkohlenstoff und Aether und setzte sich aus dem letzteren in dicken, harten Tafeln $a b$; es sublimirte beim Erhitzen in feinen, farblosen Nadeln, die ebenfalls bei $108^{\circ}$ schmolzen, und roch beim Erwärmen deutlich nach Naphtol.

Wegen ihrer Bildungsweise muss die hier besprochene Oxynaphtoësäure folgende Constitution haben:<smiles>O=C(O)C1CCCC2CCCC(O)C21</smiles>

Monochlornaphtolacton.

In die mit etwas Jod versetzte Schwefelkohlenstofflösung des Lactons wurde Chlorgas bis zur Sättigung eingeleitet, und das Lösungsmittel nachher verdunstet; der Rückstand wurde sodann in Eisessig gelöst, woraus die Verbindung in gelblichweissen Nadeln krystallisirte, die nach dem Umkrystallisiren aus Alkohol bei $184^{\circ}-185^{\circ}$ schmolzen.

0,1863 Grm. gaben 0,1299 Grm. AgCl. Gefunden:

Bereehnet für $\mathrm{C}_{10} \mathrm{H}_{5} \mathrm{ClOCO}$ :

$\mathrm{Cl} \quad 17,25$ $17,35 \%$.

Chloroxy- $\alpha$-naphtoësäure.

Das Chlornaphtolacton wurde mit verdünnter Natronlauge erhitzt, und die entstandene Lösung des chloroxynaphtoësauren Natriums mit Chlorwasserstoffsäure zersetzt, 
Ekstrand: Zur Kenntniss der Naphtoësäuren. 281 wobei ein aus gelben, feinen Nadeln bestehendes Krystallpulver ausgeschieden wurde, welcher nach Waschen mit kaltem Wasser unter Aufblähen bei $190^{\circ}-191^{\circ}$ schmolz.

$0,1818 \mathrm{Grm}$., getrocknet im Exsiceator, gaben 0,3941 Grm. $\mathrm{CO}_{2}$ und $0,0610 \mathrm{Grm} . \mathrm{H}_{2} \mathrm{O}$.

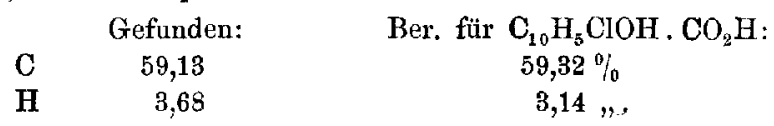

Das Calciumsalz, $\mathrm{C}_{10} \mathrm{H}_{5} \mathrm{OCO}_{3} \mathrm{Ca}$, wurde als graugrüner Niederschlag beim Versetzen der ammoniakalischen Lösung der Säure mit Chlorcalcium erhalten.

$0,1917 \mathrm{Grm}$, bei $160^{\circ}$ getroeknet, gaben 0,0940 $\mathrm{Grm}, \mathrm{CaSO}_{4}=$ $14,44 \% \mathrm{Ca}$; ber. $15,35 \% \mathrm{Ca}$.

Nach der Analyse zu schliessen, hat die untersuchte Verbindung auch etwas saures Salz $\left(\mathrm{C}_{10} \mathrm{H}_{5} \mathrm{Cl} . \mathrm{OH} . \mathrm{CO}_{2}\right)_{2} \mathrm{Ca}$ enthalten. Wenn die Mutterlauge vom neutralen Calciumsalze erwärmt wurde, schied sich noch mehr des graugrünen Niederschlages ab, was auf eine durch das Erhitzen verursachte Zersetzung der ursprünglichen Verbindung hindeutet

Monobromnaphtolacton.

Das Lacton wurde in Schwefelkohlenstoff gelöst, und zur Lösung etwas Jod und überschüssiges Brom gesetzt; sodann wurde es zur Verjagung des Lösungsmittels auf dem Wasserbade gelinde erwärmt, der Rückstand mit Alkohol gekocht und schliesslich in heissem Eisessig gelöst. Beim Erkalten wurde die Lösung mit feinen, weissen Nadeln erfüllt, die nach dem Umkrystallisiren bei $192^{\circ}$ schmolzen,

0,1775 Grm. gaben 0,1364 Grm. AgBr.

$$
\begin{aligned}
& \text { Gefunden: } \quad \text { Ber. für } \mathrm{C}_{10} \mathrm{H}_{5} \mathrm{BrOCO} \text { : } \\
& \mathrm{Br} 32,67 \quad 32,13 \% \text {. }
\end{aligned}
$$

Mononitronaphtolacton.

Das Lacton wurde mit Salpetersäure vom spec. Gew. 1,42 übergossen, und etwas rothe, rauchende Säure zugesetzt, wobei allmählich Erwärmung und Lösung eintrat; die Reaction wurde durch gelindes Erhitzen auf dem Wasserbade 
vollendet. Nach kurzer Zeit erstarrte die Lösung zu einem Brei von feinen Nadeln, die nach Auskochen mit Alkohol in siedendem Eisessig gelöst wurden, woraus die Verbindung in feinen, gelben Nadeln vom Schmelzp. $242^{\circ}$ krystallisirte. In Alkohol war sie sehr schwer löslich.

1. $0,1672 \mathrm{Grm}$, gaben $0,3852 \mathrm{Grm}$. $\mathrm{CO}_{2}$ und $0,0424 \mathrm{Grm} . \mathrm{H}_{2} \mathrm{O}$.

2. 0,1924 Grm. gaben bei $17,2^{\circ}$ und $738,5 \mathrm{Mm}$. 11,5 Ccm. N.
Gefunden:

$$
1 .
$$

O $\quad 62,85$

$\mathrm{H} \quad \mathbf{2 , 8 1}$

$\mathrm{N} \quad-$

Wie aus den Analysen ersichtlich, war die Substanz nicht ganz rein, obwohl der Schmelzpunkt auch nach verschiedenen Bereitungen constant war.

\section{Nitrooxy- $\alpha-n$ aphtoësäure.}

Das Nitrolacton löste sich leicht, besonders beim Erwärmen, in Natronlauge, und aus dieser Lösung fiel bei Zusatz von Chlorwasserstoffsäure ein gelber, krystallinischer Niederschlag aus. Bei verdünnten Lösungen schied sich der Niederschlag erst nach einiger Zeit aus, bestand aber dann aus deutlichen, rhombischen Tafeln. Die Säure zeigte denselben Schmelzpunkt wie das Lacton, nämlich $242^{\circ}$, was auf eine Wasserabspaltung durch die Hitze schliessen lässt.

0,18ऽ7 Grm. gaben bei $14^{0}$ und $755,2 \mathrm{Mm}$. $10 \mathrm{Ccm}$. N.

$\mathrm{N} \quad \begin{gathered}\text { Gefunden: } \\ 6,26\end{gathered} \quad$ Ber. für $\mathrm{C}_{10} \mathrm{H}_{5} \mathrm{NO}_{2} \mathrm{OHCO}_{2} \mathrm{H}$ :

Das Calciumsalz, $\mathrm{C}_{10} \mathrm{H}_{5} \mathrm{NO}_{2} \mathrm{OCO}_{2} \mathrm{Ca}+5^{1 / 2} \mathrm{H}_{2} \mathrm{O}$, erhalten wic das entsprechende Chloroxynaphtoat, bildete einen aus feinen, gelbrothen Nadeln bestehenden Niederschlag, der auch in heissem Wasser sehr schwer löslich war.

$0,4322 \mathrm{Grm}$., getrocknet zwischen Löschpapier, verloren bei $150^{\circ}$ 0,1172 Grm. $\mathrm{H}_{2} \mathrm{O}=27,11 \%$; ber. $26,75 \% \mathrm{H}_{2} \mathrm{O}$; der Rückstand, 0,3150 Grm., gab 0,1474 Grm. $\mathrm{CaSO}_{4}=13,77 \% \mathrm{Ca}$; ber. $14,76 \% \mathrm{Ca}$.

Der Calciumgehalt war hier wie bei der Chloroxysäure etwas zu gering, wahrscheinlich durch die Gegenwart des sauren Salzes $\left(\mathrm{C}_{10} \mathrm{H}_{5} \mathrm{NO}_{2} \mathrm{OHCO}_{2}\right)_{2} \mathrm{Ca}$ verursacht. 
In der Hoffinung, dieses saure Salz zu bekommen, habe ich die Säure selbst mit Wasser und Calciumcarbonat erhitzt, ohne jedoch dasselbe in hinreichender Menge zu erhalten.

Schlussbamerkungen.

Aus den obigen Versuchen geht hervor, dass in der $\alpha$ Naphtoësäure die in dem anderen Benzolring, mit Bezug auf die Carboxylgruppe, befindlichen $\alpha$-Stellen, also 1' und 4', am meisten substitutionsfähig sind; es hat sich nämlich herausgestellt, dass beim Nitriren nur diese Stellen besetzt werden und zwar, wie es scheint, in gleichem Maasse. Auch beim Chloriren werden nur ähnliche Monoderivate $\left(1,1^{\prime}\right)$ und $\left(1,4^{\prime}\right)$ erhalten, und es ist bis jetzt nicht möglich gewesen, andere Monoderivate zu bekommen. Von den Dinitroderivaten sind bis jetzt nur solche bekannt, die von der Mononitrosäure $\left(1,4^{\prime}\right)$ deriviren, und zwar bildet sich am leichtesten und in weitaus gröster Menge die Säure:

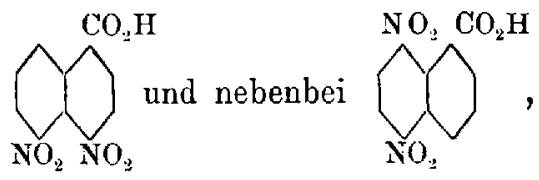

also Verbindungen, die nur in $\alpha$-Stellungen substituirt sind. Ausserdem bildet sich auch beim Nitriren der Mononitrosäure $\left(1,4^{\prime}\right)$ noch eine andere Dinitro- $\alpha$-naphtoësäure, die ihre zweite Nitrogruppe in irgend einer $\beta$-Stellung enthalten muss. Von den Dichlorderivaten ist augenblicklich nur eins bekannt, nämlich:

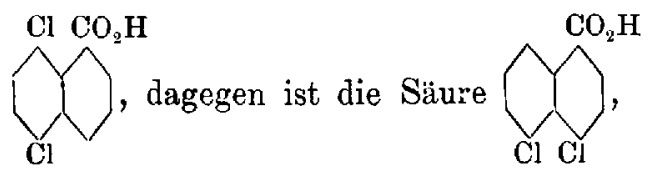

welche dem am leichtesten zu erhaltenden Dinitroderivat entsprechen würde, noch nicht dargestellt worden.

Von den drei bekannten Trinitro- $\alpha$-naphtoësäuren derivirt die eine von der Perinitrosäure $\left(1,1^{\prime}\right)$ und die zwei übrigen von der Dinitrosäure $\left(\mathrm{CO}_{2} \mathrm{H}, \mathrm{NO}_{2}, \mathrm{NO}_{2}: 1,4,4^{\prime}\right)$. 
Wie vorauszusehen ist, beeinflusst die Stellung der eingetretenen Gruppe die Eigenschaften der Verbindung, was besonders bei einigen Nitroderivaten augenfällig ist. In der Perinitro- $c$-naphtoësäure ist durch die hinzugetretene Nitrogruppe die Bindung der Carboxylgruppe sehr gelockert worden, indem starke Salpetersäure dieselbe schon ziemlich leicht austreibt. Gegen Chlor- und Bromwasserstoffsäure zeigt diese Nitrosäure ein eigenthümliches Verhalten, weil die genannten Säuren für sich allein sowohl halogensubstituirend wie auch reducirend einwirken; die Perinitrosäure verhält sich in dieser Beziehung daher wie das Chinon. Die isomere Nitrosäure $\left(1,4^{\prime}\right)$ ist ganz indifferent gegen die beiden Wasserstoffsäuren. Aus der Perinitro- $\ell$-naphtoësäure lassen sich die Alkyläther nicht durch den Alkohol und Chlorwasserstoffgas darstellen, was dagegen für die Aether der isomeren Säure leicht gelingt. Die Periamido- $\alpha$-naphtoësäure geht ungemein leicht, sogar leichter als die meisten Orthoamidocarbonsäuren, in ihr inneres Anhydrid, das Naphtostyril, über. Die Säure lässt sich leicht diazotiren und kann dadurch in die Perioxy-c $c$-naphtoësäure übergeführt werden.

Die Nitrosäure $\left(1,4^{\prime}\right)$ hält die Carboxylgruppe sehr fest gebunden, und aus ihr lassen sich mehrere Dinitrosäuren gewinnen, von denen eine mit der Zusammensetzung:

$$
\left(\mathrm{CO}_{2} \mathrm{H}, \mathrm{NO}_{2}, \mathrm{NO}_{2}: 1,4,4^{\prime}\right) \text {, }
$$

in Folge der Peristellung der beiden Nitrogruppen, beim Reduciren verschiedene, theilweise sehr eigenthümliche Verbindungen giebt. Die Diamidosäure selbst ist sehr unbeständig und verliert schon bei der Einwirkung von Chlorwasserstoffsäure Kohlendioxyd und geht in das entsprechende Diamidonaphtalin $\left(1,1^{\prime}\right)$ über. Die Ámidosäure $\left(1,4^{\prime}\right)$ kann zwar diazotirt werden, ich habe aber noch nicht die entsprechende $\mathrm{Oxy}-\alpha$-naphtoësäure daraus erhalten können, vielmehr haben sich immer bei den in dieser Richtung angestellten Versuchen intermediäre stickstoffhaltige Produkte gebildet, deren Natur und Zusammensetzung nicht hinreichend aufgeklärt sind, und welche daher in der obigen Darlegung keinen Platz gefunden haben. 
Abenius u. Widman: Ueb.d. Einwirk. d. Broms etc. 285

Während Chlor in einer Eisessiglösung der Periamido$\alpha$-naphtoësäure chlorirte Naphtostyrile, besonders das Dichlornaphtostyril, erzeugt, greift das Chlor in die Amidosäure $\left(1,4^{\prime}\right)$ unter denselben Verhältnissen ganz anders ein, indem die Amidogruppe eliminirt wird, und als Hauptprodukt das Dichlorderivat einer Naphtochinoncarbonsäure entsteht.

Upsala, Universitätslaboratorium, Juli 1888.

\section{Ueber die Einwirkung des Broms auf 0rthoacet- toluid bei hoher Temperatur; \\ $\operatorname{von}$}

P. W. Abenius und $O$. Widman.

In der Absicht, eine neue Methode für die Darstellung des o-Amidobenzylalkohols aufzufinden, haben wir die Einwirkung des Broms auf das o-Toluidin (resp. o-Acettoluid) in der Hitze untersucht. Da kochendes Toluol bekanntlich von Chlor oder Brom in der Weise leicht angegriffen wird, dass das Halogen in die Seitenkette eintritt, so konnte man erwarten, dass sich o-Toluidin in gleicher Weise bromiren lassen werde, unter Bildung von o-Amidobenzylbromid, welches nachher sehr leicht in o-Amidobenzylalkohol übergeführt werden könnte.

Es zeigte sich indessen schon bei dem ersten Versuch, dass sich das o-Toluidin selbst zu einer directen Bromirung nicht eignet. Der gebildete Bromwasserstoff verbindet sich nämlich mit dem Toluidin zu einem Hydrobromat, welches erstarrt. Nachdem die Masse bald fest geworden ist, findet kaum eine Einwirkung statt, oder wird in jedem Falle innerhalb der Reactionsmasse sehr ungleich vertheilt. Deshalb 